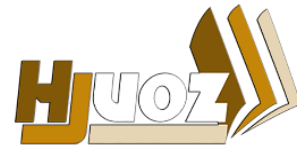

hjuoz.uoz.edu.krd p-ISSN: 2410-7557 e-ISSN: 25185128
كَّوارا زانستيّن مروّقايهتى يا زانكوّيا زاخوّ

مجلة العلوم الانسانية لجامعة زاخو

Humanities Journal of University of Zakho (HJUOZ)

Vol. 5, No. 4, pp. 1094-1110, December-2017

\title{
إثكاليات التفاوض الكوردي مع الحكومات العراقية المتعاقبة من وجهة نظر نخبة من المثقفين الكورد " للفترة 1921 - 1992 في اقليم كوردستان العراق"

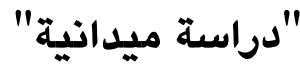 \\ ميران محمد صالح
}

قسم التاريخ، كلية التربية الاساس، جامعة سوران، اقليم كوردستان - العراق.

https://doi.org/10.26436/2017.5.4.500 2017/12 2017 2017/11 تاريخ الاستلام: 201/

الملخص:

يسعى هذا البحث الى معرفة كيفية سير العملية التفاوضية التي اجرتها القيادات الكوردية، منذ تاسيس دولة العراق عام 1921 مع الحكومات العراقية ولحد عام 1992، بأعتبارها عملية اجتماعية وسياسية، من وجهة نظر نخبة من المثقفين الكورد في اقليم كوردستان العراق، ومحاولة تقويم العمليات التفاوضية في ضوء التغيرات والنتائج التي يمكن ان يراها هؤلاء النخبة من اجل تطوير مستقبل المجتمع الكوردي. وتتجلى أهمية الموضوع من خلال محاولته معرفة واقع التفاوض الكوردي ونقاط الضعف والمعوقات التي كانت تواجهه اثناء المفاوضات مع الحكومات العراقية المتعاقبة. فضلاً عن ذلك تأتي أهمية هذه البحث من كونه دراسة علمية ميدانية في نطاق (علم الاجتماع السياسي) من ناحية، ويمكن الاستفادة منه في اقسام علم الاجتماع والسياسة من ناحية أخرى. وتتجلى أهمية هذا البحث كذلك في كونه الدراسة الأولى في كوردستان العراق (حسب علم الباحث) التي تتناول على وجه التحديد مشكلة التفاوض الكوردي من وجهة نظر نخبة من فئات المجتمع الكوردي. ويسعى البحث الى التوصل الى عدة اهداف منها: اولا: عرض وتشخيص مباديء التفاوض وأهمية العلاقات الدبلوماسية والوضع السياسي والتأريخي والاقتصادي للثورة الكوردية في سير المفاوضات. ثانيا: محاولة نشر الوعي السياسي حول هذه المسألة للعاملين في السلك الدبلوماسي والعلاقات الدولية وتحديد نقاط الضعف في المفاوضات السابقة.

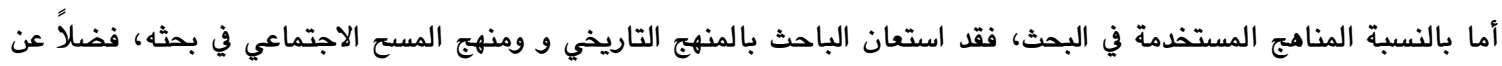
الأدوات المستخدمة، والتي هي (الاستمارة الاستبيانية والمقابلة)، وان (عينة البحث) التي تم استخدامها هي (عينة قصدية) شملت (278) مثقفاً من محافظات اقليم كوردستان العراق. وتوصل البحث الى عدد من النتائج أهمها: اولاً: أن نسبة (.77.39\%) من افراد عينة البحث يؤكدون على ان القيادات الكوردية لم تعتمد أو لم تهتم بالمثقفين والمتنورين المستقلين في المفاوضات التي استمرت قرابة (قرن) من الزمان استغرقتها المفاوضات مع الحكومات العراقية. ثانياً: لقد أكدت نسبة (80.21\%) من عينة البحث ان الاختلاف، و تقاطع المصالح بين قيادات الاحزاب الكوردية كان احد الاسباب الرئيسية للفشل وعدم حصول الكورد على ما كانوا بنوون الحصول عليه في مفاوضاتهم مع الحكومات العراقية. ثالثاً: أن نسبة (87.40\%) من عينة البحث أكدت على ان عدم الاهتمام أو اهمال مسألة توزيع نفوذ الدول الكبرى في العالم، وخاصة في الشرق الأوسط من قبل القيادات الكوردية في مفاوضاتهم كان أحد الاسباب في عدم توصل القضية الكوردية الى الحل. رابعاً: إتضح من نتائج البحث أن (. \%8.12) من المبحوثين اكدوا على أن تغير انظمة الحكم في العراق لم يؤثر على رؤية ومواقف الحكومات العراقية في حل القضية الكوردية عن طريق المفاوضات. الكلمات الدالة: الاثكالية، التفاوض الكوردي، الحكومات العراقية، المثقفين، اقليم كوردستان العراق. والاجراءات والمستويات، وفي هذا العصر أصبحت موضع اهتمام كل من السياسيين والعسكريين والاقتصاديين والاكادميين في العالم وعلى المستوى المحلي والخارجي بحيث وصلت الى درجة اصبحت لها مؤسسات خاصة ونظام ووسائل وأبعاد وقانون ليجعل بأمكان كل

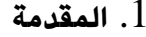

ان الدبلوماسية والمفاوضات، بأعتبارهما عملية اجتماعية وسياسية قام بها الانسان على مرّ التأريخ بشكل ومستوى مختلفين، مع تطور وتقدم المجتمعات الإنسانية، وقد جرت عليها تغيرات في الوسائل 
3.2 يسعى البحث الى تحقيق عدة أهداف منها: 1- معرفة تأثير اختلاف وتقاطع المصالح بين القيادات الكوردية في فشل المفاوضات. 2- مذا البحث محاولة في هذا المجال ، لان هذا الموضوع لحد الآن لم يكن موضوعاً لأي بحث علمي.

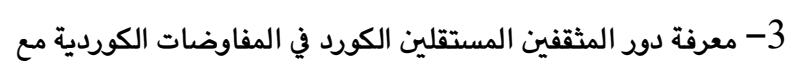
الحكومات العراقية المتعاقبة. 4- محاولة نشر الوعي السياسي في مذه المسألة للعاملين في السلك الدبلوماسي والعلاقات الدولية ويالأخص الكورد منهم. 4.2 فرضيات البحث: انطلق البحث من الفرضيات الآتية:1- مل كان لمصالح الخاصة للقيادات الكوردية دورا في مفاوضات؟. 2- مل كانت قيادات الكوردية حسبت حسابا للصراعات الدولية والنفوذ الدولي في المنطقة وتأثيرها في مسيرتها النضالية؟. 3- إن نظرة النخبة المثقفة للمتفاوض الكوردي سلبية بسبب عدم وجود فريق متفاوض موحد. 4- لقد كان اعتماد قيادات الكوردية في مفاوضاتهم على المثقفين

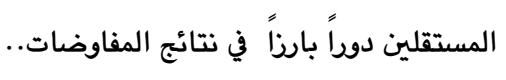

5.2 المصطلحات العلمية للبحث: 1.5.2 التفاوض: Negotiations : إن عملية التفاوض أشبه بلعبة شد الحبل حيث يوجد فائز واحد فيها، مما يعني أن يكون الطرف الآخر هو الخاسر ولابد، ويرى كثير من الناس بأن التفاوض هو وسيلة للتوصل لأتفاق، مما يعني بأنه ليس هناك منتصر ولا خاسر.إذن نستطيع نقول بأن التفاوض يهدف أساساً إلى الحصول على شيء أفضل مما كنت تحصل عليه من غير التفاوض. ويعرف كندي (Kennedy) التفاوض بأنه العملية الخاصة بحل النزاع بين طرفين أو أكثر، والذي من خلاله يقوم الطرفان (أو جميع الأطراف) تعديل طلباتهم، وذلك بغرض التوصل إلى التسوية المقبولة

$$
\text { و تحقيق المصلحة لكل منهما(1). }
$$
ولكن (محمد علي) يعرفه بأنه عبارة عن تبادل مجموعة من الناس لأفكارمم وأرائهم حول موضوع معين لتحقيق التعاون، أو تقوية أواصر

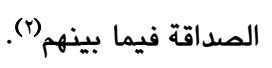
أما تعريفنا للتفاوض في هذا البحث فهو (عبارة عن تلك العملية التي تهدف إلى حل النزاع بين طرفين (الطرف الكوردي- والحكومات العراقية المتعاقبة) بغرض التوصل الى تسوية المشاكل بينهما وتحقيق

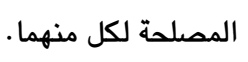

وحدة سواء كانت محلية او دولية أن تعرف عليها ومراعاتها في مجال التطبيق. والشعب الكوردي شأنه شأن شعوب العالم، في تاريخه القديم والحديث قد قام بالتفاوض في حالات كثيرة وأستفاد من الإجراءات والوسائل المتاحة له بشكل مختلف. صحيح التفاوض الناجح له شروط وأسس وأرضية خاصة به لذلك اهتمت به الدول وجعلت له المؤسسات والهيئات الخاصة به، وفي مذا الاتجاه عملت الحكومات العراقية المتعاقبة، ولكن في مفاوضاتها مع الع ودات قادة الكورد وفي الكثير من الحالات اعتمدت على اشخاص عسكريين وحزبيين، وسبب ذلك مو أن الشعب الكوردي في كثير من المراحل

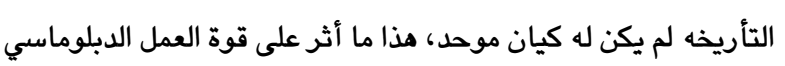
في معاملاته مع الدول المحتلة لكوردستان. 2. الاطار العام للبحث

1.2 يرجع السبب الرئيسي لإختيار هذا البحث إلى عدم وجود بحثِ أكاديمي (علمي) خاص في هذا المجال وفي إطاره التاريخي وعلى وفق منهج

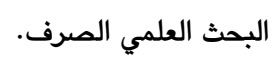
مع الأخذ بنظر الاعتبار أهمية الكثير من الكتابات السابقة في مذا

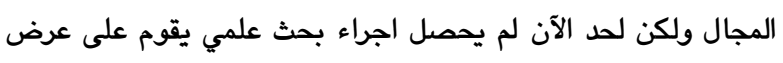
وتحليل وتقيم ومقارنة موضوع بحثنا بشكل موضوعي صرف. 2.2 1- إن أدبيات العلوم الاجتماعية والسياسية في الشرق الأوسط بصورة عامة وكوردستان بصورة خاصة تعاني من عدم وجود البحوث الميدانية التطبيقية حول موضوع (التفاوض).

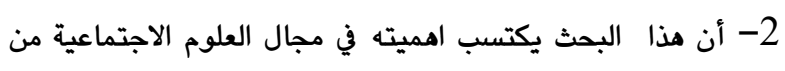
محاولته معرفة واقع التفاوض الكوردي ونقاط الضعف والمعوقات،

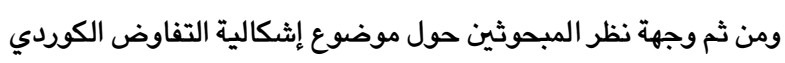
مع الحكومات العراقية المتعاقبة. 3- فضلاً عن ذلك تأتي هذا البحث من كونه بحثا علمياً ميدانياً في نطاق علم الاجتماع السياسي في ناحية ويمكن الاستفادة منه في أقسام علم الاجتماع والسياسة من ناحية أخرى. 4- تتجلى أهمية مذا البحث كذلك في كونه البحث الأول في كوردستان العراق والذي تتناول على وجه التحديد مشكلة التفاوض الكوردي من

$$
\text { وجهة نظر نخبة من المثقفين الكورد. }
$$

5- إذا كانت الحرب فن الإكراه فإن المفاوضات هي فن الاقتناع، لذا فإن لهذا البحث أهمية خاصة، بالنسة للكورد، لكون المفاوضات أصبحت إحدى المفاهيم الإستراتيجية في قاموس سياسة بالقيادة

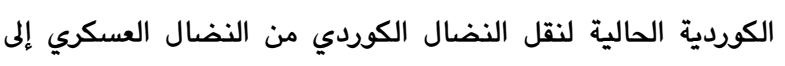
الدبلوماسي وانتهاج أسلوب المفاوضات في تسوية القضية الكوردية. 
4.5.2 المثقف: Intellectuals : أن كلمة المثقف ليست ذات مدلول معين وانما مدلولات تتغير حسب المجتمع نفسه وحسب درجة

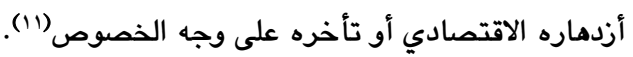

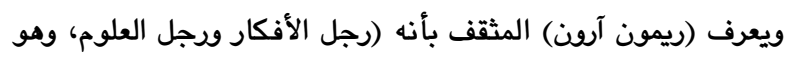

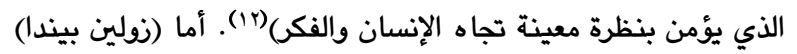
فيرى بأن المثقفين (هم زمرة صغيرة يسميهم بملوك الفلاسفة) وهم

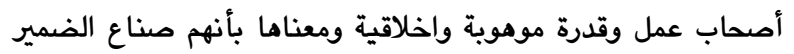
الانساني)(1r) (1T) ويعرفه (سليم) بأنه. كل من امتلك القدرة على الانتاج الثقافي سواء

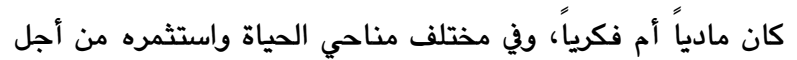
انجاز وتحقيق النقلة الاجتماعية للمجتمع الكوردستاني بشكل يؤدي الماني

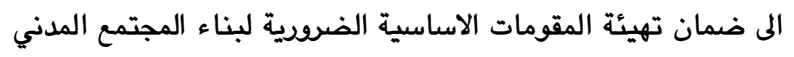
في كوردستان العراق و مواكبة المسيرة الانسانية للمجتمعات المتقدمة(1) (1). أما التعريف الاجرائي للمثقف في هذا البحث فهو (عبارة عن تلك النخبة من المواطنين. الذين لهم القدرات والخبرات والمهارات في تحليل

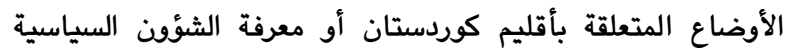

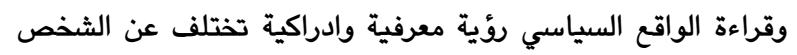
العادي، الذي لا يمتلك هذه الثقافة).

\section{3. ماهية التفاوض السياسي}

\section{3 نبذة تأريخية عن التفاوض:}

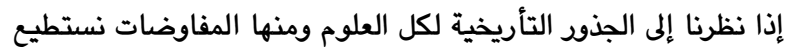
ويسهولة أن ندرك أنها كانت مرتبطة بوجود آدم (عليه الصلاة

$$
\text { والسلام) (10). }
$$

فقد وجدت العمليات التفاوضية منذ القدم، مرتبطة بشكل مباشر

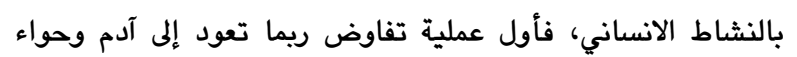
عليهما السلام(17). أما في الحضارات القديمة فنجد إن المفاوضات قد تزامنت وجوداً مع وجودما(1). فهي السلوك الاجتماعي الفطري الذي نشأ كوسيلة للأتصال و التفاهم بين المجتمعات البشرية والمجاورة في العصود القديمة(1). فقد مارسوا التفاوض على أساس أنه جزء من العادات والأخلاق والتقاليد وتعزيزاً للتعاون والأستقرار والسلم والحماية(19).

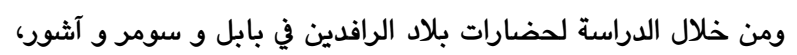
نلاحظ أن الانسان في تلك الحضارات أمتهن التجارة منذ أكثر من خمسة ألاف سنة، ويوثق ذلك كثير من الوثائق والصكوك والعقود التجارية ومذه العلاقات تتم في الغالب بواسطة المفاوضات(20). ونتيجة للتطور فقد نشأت علاقات جديدة آدت إلى زيادة الحاجة إلى الأتصال فبرزت العمليات التفاوضية كوسيلة ملبية لهذه الحاجة

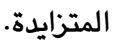

2.5.2 السياسة: Politics: تمثل السياسة في يومنا الحاضر، مسألة ذات أهمية كبيرة، ليس للمشتغلين بها فقط وإنما للمتخصصين بالعلوم الاجتماعية أيضاً، حتى أصبح عالم اليوم هو عالم السياسة. وترجع كلمة السياسية في اللغة العربية، إلى فترة تأريخية قديمة، ولعل الع المائ أول من أورد كلمة (السياسة) هو (أبو مليكة) جرول العبسي المعروف بـ(الحطيئة في مدح بغيض بن لؤي الشماس) (r). ولكن تباينت معاني

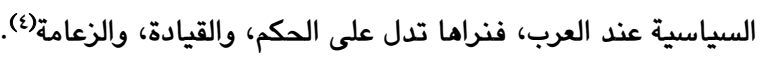
أما مصطلح السياسة في اللغات الغربية ومنها الانكليزية Politics Polis, وهما مشتقات من تسميات لاتينية Politique والفرنسية ومنية (.) Politica, Politike ويعرفها د. حسن الترابي (هي إدارة أمر تقضي ضبطاً وتدبيراً يصلح شأنه) (7). بينما يعرفها (دوفرجية) (بأنها علم السلطة المنظمة في الجماعات الإنسانية كافة)، وجاء في القاموس الامريكي (بأنها هي إحدى العلوم الاجتماعية التي تبحث في النظرية والتعليق السياسي، وفي نظم الحكومة والإدارة)(V) أما تعريف السياسة في هذا البحث فهو (عبارة عن تلك الايدولوجية السياسية التي تدير السطة في إقليم كوردستان-العراق في تعاملها مع المواطنين في الداخل وعلاقاتها مع الدول الأخرى في الخارج. 3.5.2 النخبة: : Elite هي مفهوم اجتماعي إنتقل إلى علم السياسة عن طريق علماء الاجتماع السياسي ويختلف من مجتمع الى آخر، ففي المجتمعات الديمقراطية هناك عدد من النخب داخل النظام السياسي، والتي تهدف إلى حدوث التوانن بين المصالح (للنخب الاجتماعية والسياسية، ونخب رجال الأعمال) وفي المجتمعات غير

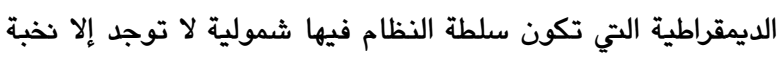
واحدة هي النخبة السياسية التي تتحكم بحكم سلطاتها غير المحدودة في كل من الاقتصاد والاجتماع وغيرها. والنخة عند (باريتو) هي النخبة الحاكمة، وهي تضم أولئك الذين يؤدون دوراً ملموساً ومباشراً في إدارة شؤون الحكومة، والنخبة غير الحاكمة ، وهم أعضاء طبقة النخبة كافة في معناها الواسع(()). ويقصد بالنخبة (تلك المجموعة من الأفراد الذين يحتلون مواقع مؤثرة في عملية صنع القرار الاجتماعي أو الاقتصادي أو السياسي أو كلها مجتمعة)(9) و يعرف (كارلوس آلبرتو) النخبة (بأنهم الجماعات التي تتولى قيادة وإدارة القطاعات الرئيسية للمجتمع أي أولئك الذين يتصرفون باسم بعض القيم والاتجاهات والايديولوجيات) (.1.) أما النخبة في مذا البحث فهي (مجموعة من الأشخاص الذين يتمتعون بخصائص غير موجودة لدى بقية أفراد المجتمع الكوردي ويمثلون قيادات الأحزاب السياسية، وأعضاء البرلمان، ورجال الاعمال وأساتذة الجامعات والأكاديميين المختصين في العلوم السياسية، واعلاميين واعضاء المنظمات المجتمع المدني والمهتمين بالسياسة). 
إلى المفاوضات من وجهة نظر الطرف الآخر. 10- الثقة بالنفس القائمة على أساس المعرفة والتخطيط والتفاوض بطريقة سليمة. 11-

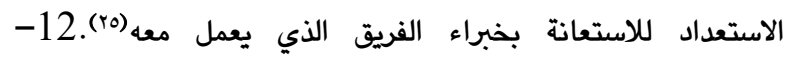

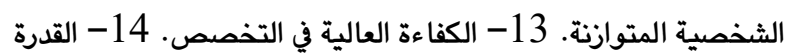
العالية على العطاء. 15- الإتجامات الايجابية نحو الآخرين ونحو التفاوض. 16- قوة الشخصية والثقة بالنفس. 17- التوازن العاطفي وعدم العصبية. 18- المهارات المتميزة في الاتصال والإنصات. 19المهارات العالية في الإقناع. 20- التفكي الإبتكاري. 21- القدرة على تحليل المشكلات. 22- مهارات التصرف في المواقف الصعبة. 23عدم الغيرة(r7). 24- الخصائص الموضوعية (القدرة على التحليل ، المعرفة الاقتصادية، و المعرفة القانونية، والمعرفة اللغوية، والمعرفة

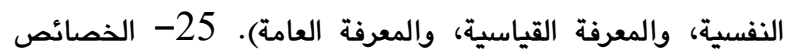
الشخصية ، (قوة التحمل، ونضج الشخصية، الذكاء والدهاء، حسن التصرف وسرعته، إجادة فن الاستماع والاتصال، اللياقة والكياسة، سرعة الملاحظة والفطنة، الادراك الشامل والكامل) (rv). 3.3 واقع التفاوض السياسي الكوردي: على الرغم من أن الأوربيين يرون أن المفاوضات أساسها يعود منذ

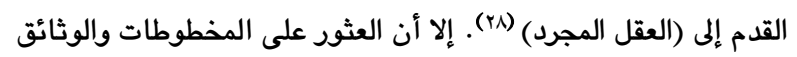
في بعض المناطق الآثرية تؤكد بأن الشعب الكوردي القاطن في منطقة الشرق وغرب وجنوب بحيرة (وان)، والتي تتألف من أقليمين احدهما (سو) والآخر (كردا) هو في مقدمة الشعوب التى راغب هذا النمط من

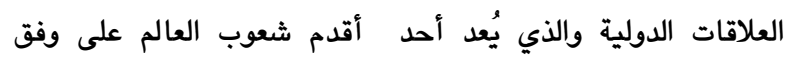
النصوص المسمارية في عهد الملك (ثوسين) بين أعوام (20362038) ق.م، ويحكم الموقع الجغرافي لهذا الشعب كان يقع فيه العديد من الحروب والصراعات التي كانت تستلزم بالضرورة إجراء وممارسة المفاوضات لغرض حلها وتسويتها، ومن آهم القبائل الكوردية المشهورة بالمفاوضات هم (لولوييون) الذين أسسوا إمارة (خمازي) وكانوا يقطنون في (سليمانية) وأتخذوها عاصمة لهم في الألفية الثالثة قبل الميلاد، إذ أنهم كانوا يتفاوضون باستمرار مع دولة (إبلا) في مدينة حلب السورية، وكذلك الحال بخصوص دولة (كاشي) الكوردية بقيادة الملك (بورتا يورياش الثاني) مع المصريين القدامى في عهد فرعون (أخناتون) (الأمينونيس الرابع) خلال الأعوام (1345-1375) ق.م، وكذلك بين الميتانيين الكورد والمصريين القدامى في عهد الامارة الثامنة عشرة المصرية(r9)، وينقسم واقع التفاوض الكوردي في العصر

$$
\text { الحديث الى مرحلتين وهما:- }
$$

1.3.3 المرحلة الاولى: لقد قام (الشيخ محمود الحفيد) قبل اندلاع الحرب العالمية الأولى وأثنائها بعدد من الأتصالات مع الدول ذات النفول في المنطقة منها الروس و البريطانيين، وحتى مع شريف مكة وأولاده، ولكن دون أي نتائج(·r). ويعد تشكيل أول حكومة في كوردستان في
أما عند العرب في الجاملية، فكانت طبيعة العرب المتمثلة في حب الأسفار والتنقل بسبب الظروف الاقتصادية والاجتماعية والجغرافية الصعبة، دفعتهم إلى ممارسة التجارة وإلى المفاوضات في الأسواق (كسوق عكاظ) ، والأندية لرؤية المواسم الثقافية والدينية، وسهلت عليهم إقامة العلاقات والارتباطات الواسعة، الأمر الذي أدى إلى ظهور الحاجة إلى إرسال الوفود لتقديم التهاني والتعازي، أو للتشاود أو لعقد إلدات التحالفات على النجدة وفقاً لطبيعة المناسبة، مثل حلف الفضول(1)( أما المفاوضات في الاسلام، فكانت في بداية انطلاق الدعوة الاسلامية كان (صلى الله عليه وسلم) يجريها مع مشركي مكة مثل (صلح الحديبية) ولكن بعدما أشتد عود الاسلام، وجدت قريش أن لا سبيل للتفامم مع محمد (صلى الله عليه وسلم) إلا بالمفاوضات كتلك التي دارت بين (الرسول وسهيل بن عمرو)، وقد دخل المسلمون في مفاوضات شتى مع دولتي الساسانية والروم، في عهد الخلافة

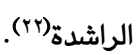
أما في العصر الأموي، فكانت المفاوضات وسيلة من وسائل تنفيذ السياسة الخارجية للدولة، أما في العصر العباسي، فمرت المفاوضات بتطورات جديدة لم تعرف من قبل، فبلفت درجة عالية من التقدم بحيث أصبحت تخضع لقواعد دقيقة وأسس وأصول واضحة، فكانت بغداد تعج بالوفود، ومن أشهر المفاوضات في التأريخ الاسلامي تلك التي تمت بين صلاح الدين الايوبي وريتشارد قلب الأسد عام (587-

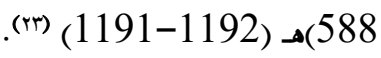
أما في العصر الحديث فكان الكتّاب والمهتمون بعلم التفاوض كثيراً ما يشيون الى مقالات (السيد فرانسيس بيكون) (1626-1561) وكتاب (ميكافيلي) الأمير 1513م الذي عالج فيه حيل الحكم

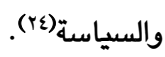

إما في يومنا هذا فقد أصبحت للمفاوضات معاهد متخصصة هدفها تدريس فنون التفاوض وقواعده وأسسه ومرتكزاته، وتخريج

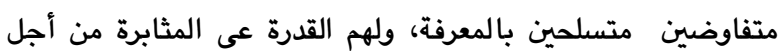
الوصول إلى الحلول لكل النزاعات.

2.3 شروط التفاوض الناجح: ويرى (محمد عبدالغني حسن ملال) وآخرون بأن هناك شروطاً لابد من توفرها عند المفاوض الجيد ومنها:1- القدرة على التفاوض بفاعلية. 2- الاستعداد والالتزام بالتخطيط والقواعد والبدائل والتأكد من صحة المعلومات. 3- الحكم السليم، والقدرة على التمييز بين القضايا الأساسية وتحمل الصراعات. 4الشجاعة والالتزام الشخصي بالوصول إلى الأهداف العليا. 5- الحكمة والصبر ومن ثم الانتظار حتى تظهر الرؤيا بأكملها. 6- الاستعداد للمشاركة مع الخصم ومع الزملاء في الشراكة. 7- الالتزام بالنزامة. 8- القدرة على الاستماع بعقل منفتح. 9- امتلاك القدرة على النظر 
واتفاقية 3-1932/5/5 مع الانكليز بقصد تبادل الأسرى ولكن كل

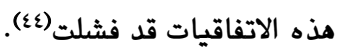
ومع انتفاضة البارذان الثانية في عام 1943 و حتى حتى سقوط الاتفات الحكومة الملكية في العراق عام 1958 وعودة البارزاني من الاتحاد السوفيتي أجري عدد من الاتفاقيات ولكن دون أن يكون عند الحكومات العراقية والمسؤولين البريطانين نية لحل القضية الكوردية. ومنها: 1- 1-المحادثات التي اجريت في 1943/11/29. 2- الاتفاقية التي جرت في 1943/12/25. 3- 3 المحادثات التي جرت في 3/24-1945/5/7. ويعد اختيار ملا مصطفى البارزاني رئيساً لحزب وعقد أول مؤتمر

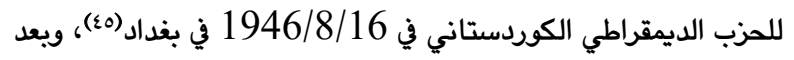
سقوط جمهورية كوردستان في مهاباد في 1946/12/31 زار ملا مصطفى البارزاني شاه ايران لمناقشة مصيرهم في ايران(1)؛. ولكن

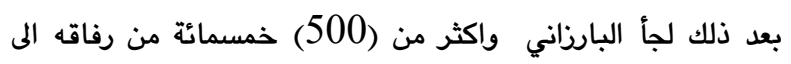
الاتحاد السوفيتي (عv). وفي خلال فترة 1954-1958 زار البارزاني كل من (تشقند و أرمينيا و رومانيا وجيكوسلوفاكيا، ومصر، والتقى بكبار المسؤولين في تلك الدول لأطلاعهم على القضية الكوردية) (^ع). وبعد سقوط النظام الملكي واعلان الجمهورية في عام 1958 ورجوع ملا مصطفى البارذاني بدأت مرحلة جديدة من الكفاح للشعب الكوردي. والمقابل رحبت القيادة الجديدة في العراق بموقف القيادة الكوردية وأعلنت تمسكها بحل سلمي للقضية الكوردية، ولكن الأيام أظهرت عكس ذلك، وأجريت عدد من المحادثات والمفاوضات والاتفاقيات ولكن الكاتية الكردية كانت كلها حبراً على الورق.

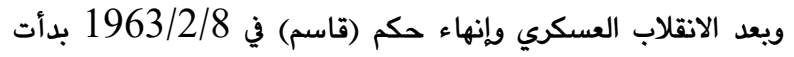
مرحلة جديدة من التأريخ السياسي في العراق والحركة الكوردية في جنوب كوردستان، وأرسل (الحزب الديمقراطي الكوردستاني) برسالة يوضح فيها بأن موقفهم مرهون بأعتراف السلطة الجديدة بحقوق الشعب الكوردي في إطار الحكم الذاتي. ولكن السلطة الجديدة قد أكدت

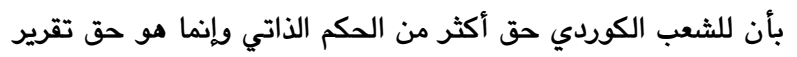
المصير(؟9). (ب9) ولكن بعدما جاء البعثيون الى السلطة لم يعترفوا بتلك الحقوق للشعب

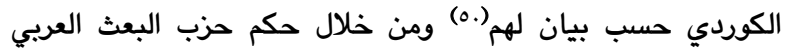

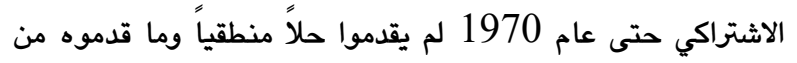
الوعود لحل المشكلة الكوردية تراجعوا عنه بعد تحسن أوضاع الحزب لماتي وسلطتهم في الحكم والتأريخ مليء بمثل هذه المواقف، وخلال فترة حكمه لم يستطيعوا حل القضية الكوردية حيث جرت مفاوضات كثيرة ولكن دون جدوى، ومن هذه المفاوضات: (1-1963/2/18 (1963/12/16).

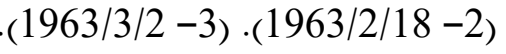

1918/11/17 ارسل الشيخ محمود برسالتين الى المسؤولين

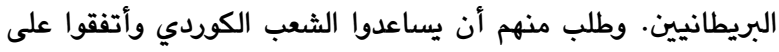
سبع نقاط ولكن بريطانيا لم تطبقها في النهاية(1). وفي 1918/12/1 تم اجراء المحادثات مرة أخرى بين البريطانيين والشيخ محمود وست من رؤساء العشائر في كوردستان الجنوبية، وتم التوصل إلى اتفاقية شفهية تحدد نوع ومستقبل العلاقة بين الكورد ودولة العراق الجديدة. ولكن لم تنجع هذه الاتفاقية بعد ذلك (rآ). مما أضطر الشيخ في هذه الظروف إلى أن يلجأ الى كل من روسيا وأمريكا وتركيا (Tr). وفي عام 1922/10/9 تشكلت الحكومة الكوردية الثانية(ז). وخلال تلك الفترة التقى الشيخ محمود بالمسؤولين الاتراك ففضب البريطانيين من هذا التصرف. على الرغم من ذلك بقى باب الحل الدبلوماسي

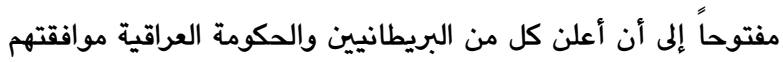

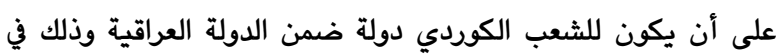
1922/12/21 ولكن لم يطبقا هذه الاعلان. (ro).

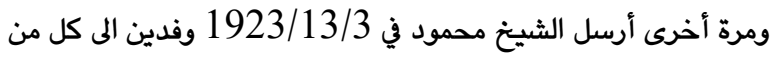

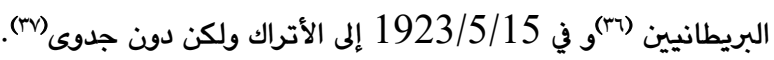
وفي تموز من عام 1923 تم تشكيل الحكومة الكوردية الثالثة تحت

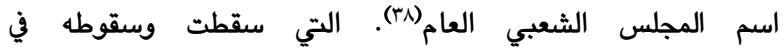
1924/7/19 (ra). استمر الشيخ محمود في محاولاته الى أن تم الاتفاق

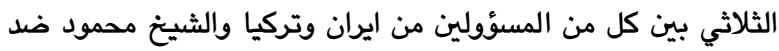

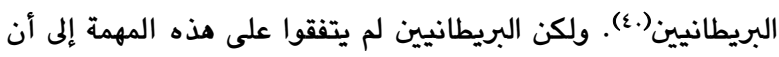
اتفقوا مع الشيخ محمود لوقف اطلاق النار بشرط أن يقطع الشيخ محمود علاقته مع تركيا. ولكن بعد ذك طلب من الشيخ أن يعتزل العمل السياسي، ومن طرف آخر طلب البريطانيا من ايران ان تضغط

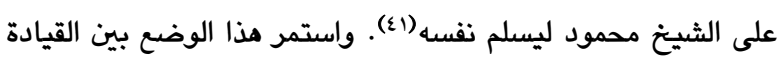
الكوردية (الشيخ محمود) والبريطاني على هذا المنوال من المحادثات المفاوضات والفشل دون أن يحصل الكورد على شيء في هذه المحادثات غير استغلال الوقت من قبل عدوهم ففي سنة 1929 تم تم إجراء اجتماع بين الشيخ محمود وستة من رؤساء العشائر الكوردية، وفي سنة 1930 بين الشيخ محمود و البريطانيين، واستمرت الحالة إلى اليوم الذي قبض فيه على الشيخ محمود من قبل الانطليز في (42) 1931/5/14

2.3.3 المرحلة الثانية: ومن جانب آخر كانت منطقة بارزان إحدى المناطق للحركة التحرية الكوردية وخاصة بعد الحرب العالمية الأولى ودمج جنوب كوردستان بدولة العراق الجديدة، فكان لها دور بارذ في تأريخ الحركات التحرية الكوردية، بدءاً من إعدام (الشيخ عبدالسلام لئام البارزاني) في 1914/12/14 (r)، أو عصر الشيخ أحمد البارزاني وقيام الانتفاضة في مناطق البارزان والاتفاقية المؤقتة في 1931/12/3 مع الحكومة العراقية لوقف اطلاق النار لمدة اسبوعين. 
ولكن في (5) آذار من عام 1991 عمت انتفاضة شعبية مسلحة ضد الحكومة العراقية في الجنوب وأرجاء كوردستان العراق، بعد هزيمة الحكومة العراقية ، في حرب الخليج الثانية، وردت الحكومة العراقية بالقوة، مما ادى إلى فرار أكثر من مليون كوردي إلى جبال تركيا وإيران(م) بان. وفي (5 نيسان) من عام 1991 أصدر مجلس الأمن القرار المرقم 688 يطالب فيه العراق بتسهيل إمداد الكورد بالمعونة الانسانية، وفي

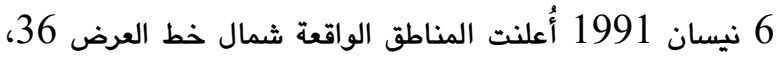
منطقة محرمة على الطائرات العراقية (الملاذ الامن) (09). وفي اثناء مذه الفترة تمت المفاوضات بين القيادات الكوردية (السيد مسعود البارذاني والسيد جلال الطالباني) من طرف والحكومة العراقية من طرف آخر لحل القضية الكوردية واستناداً إلى اتفاقية عام 1970 التي لم تطبق الحكومة العراقية بنودها، ولكن استمرت هذه المفاوضات لأكثر من سنة، وكعادتها لم تعترف الحكومة العراقية تحت مسميات عدة بالحقوق القومية للشعب الكوردي)(.7). ويعد ذلك جرت أول انتخابات كوردية، مستقلة عن الحكومة العراقية لتكوين برلمانهم في 19 مايو 1992 وأستمر هذا الوضع بين الحكومة العراقية وحكومة اقليم كوردستان إلى سقوط النظام البعثي في بغداد في 2003 ويدأت المرحلة الجديدة في التأريخ السياسي في العراق وللشعب الكوردي والشعوب العراقية كافة(7)

\section{4. الاجراءات الميدانية}

1.4 منهجية البحث: Research Method: بما أن مشكلة هذا البحث تتعلق بـ(إثكالية التفاوض الكوردي مع الحكومات العراقية المتعاقبة من وجهة نظر نخبة من المثقفين الكورد-

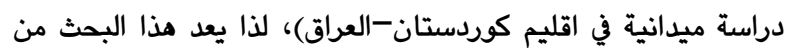
البحوث الاجتماعية الوصفية التحليلية ويعتمد هذا البحث على جمع الحقائق وتحليلها وتفسيرما لأستخلاص نتائجها وقد استخدم الباحث

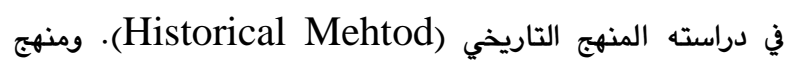
المسح الاجتماعي Social Survey Methed.

$$
2.4 \text { مجتمع وعينة البحث: }
$$

1.2 .4 عبارة عن كل الوحدات أو الاثياء أو الأفراد الذين يكونون موضوع البحث، أو جميع العناصر التي لها علاقة بمشكلة البحث ، والباحث يريد تصميم نتائج البحث عليها من السياسيين والاكاديميين والحقوقيين من مختلف شرائح الاجتماعية في المجتمع مثل (اصحاب الخبرة والصحفيين والاساتذة الجامعيين....) (ז'). ومجتمع البحث في هذه البحث يشــــمل نذبة من المثقفين الكورد الموجودين في اقليم كورد ستان - العراق من كلا الجنسين ممن كانوا اعماره من (35) سنة فما فوق من المجتمع البحث.
ويعد اعلان وقف اطلاق النار بين الثورة الكوردية والحكومة العراقية في 1964/2/10 كان من المنتظر ان يكون هذا الاتفاق خطوة الى الامام وارضية صالحة لحل القضية الكوردية ولكن تبين العكس، اذ وصلت العلاقة بين قادة الحزب الديمقراطي الكوردستاني الى وضع سيء

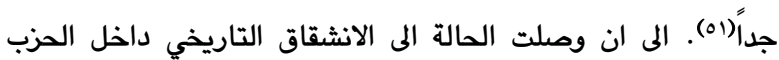
والذي عرف بأنثقاق جناح المكتب السياسي بزعامة (ابراهيم احمد

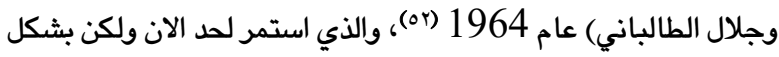
مختلف . اتفق جناح المكتب السياسي في الحزب الديمقراطي مع الحكومة العراقية في 1966/6/16، ولكن رغم الاتفاقية التي حصلت بين الاطراف الكوردية والحكومة العراقية في 1966/6/29 فقد بدأ هذه المرة صراع مسلح بين الاطراف الكوردية،(بr). ولكن الانقلاب العسكري للبعثين للمرة الثانية في 17-1968/7/30 قد انهى كل مذه المفاوضات ويدأت مرحلة جديدة في العراق وللحركة الكوردية (ه). ويذلك بدأت مرحلة جديدة من التأريخ السياسي في العراق وللحركة الكوردية بقيادة (ملا مصطفى البارذاني) ، ففي 11 آذار من عام 1970 تم عقد اتفاقية بين الحكومة العراقية والثورة الكوردية لحل القضية الكوردية واعطاء الحكم الذاتي للشعب الكوردي وسميت باتفاقية آذار 1970، ولكن بعد أريع سنوات من مدة تنفيذ بنود الاتفاقية وخلال هذه المدة استطاعت الحكومة العراقية ان تتسفيد من هذه الهدنة وجرت الاتصالات السرية بين الحكومة العراقية والحكومة الايرانية لقطع مساعدة الاخيرة للثورة الكوردية، وتم التوصل في دولة الجزائر بمساعدة الرئيس الجزائري أنذاك (هواري بومدين) ما سميت بـ(اتفاقية الجزائر) المشؤومة بالنسبة للثورة وللشعب الكوردي في عام 1975 ويذلك فشلت الثورة الكوردية أنذاك(00).وفي ألاول من حزيران عام 1975 تشكل الاتحاد الوطني الكوردستاني بقيادة جلال الطالباني(07). وفي عام 1983 بدأت المحادثات بين حزب الاتحاد الوطني الكوردستاني بزعامة جلال الطالباني والحكومة العراقية على القضية الكوردية ولكن بعد أكثر من سنة فشلت المفاوضات بسبب عدم اعتراف الحكومة العراقية بمطالب الشعب الكوردي. الا أنه بسبب اوضاع السيئة لكوردستان من جراء العمليات العسكرية للحكومة العراقية خاصة بعد انتهاء حرب العراقية -الايرانية من جانب ومن جانب آخر بسبب الاوضاع السياسية الكوردستانية والاقليمية والدولية، راى قادةالاحزاب الكوردية من الافضل ان يشكلوا في هذه المرحلة جبهة كوردستانية وان يضعوا خلافاتهم جانباً ويهتموا بالمصالح العليا للوطن و والشعب الكوردي. فتوصلوا الى تشكيل واعلان الجبهة الكوردستانية في 1988/6/6 (ov). 
وتبين ان معدل مذه النســـبـ مي (92\%) وكان صـــدق الاداة (\%88.38)

ب- المقابلة وقد ثم اعتماد المقابلة من قبل الباحث بوصفها طريقة علمية لجمع البيانات وقد قام الباحث بمقابلة عدد من الشخصيات السياسية والكاديمين في مجتمع الدراسة. 4.2.4 مجالات البحث: أ- المجال المكاني: ينحصر المجال المكاني للبحث بمنطقة أقليم كوردستان -العراق التي تشمل المحافظات الثلاثة الرئيسية (أربيل-

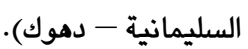
ب- المجال البشري: شملت عينة البحث (278) فرداً من سكان أقليم كوردستان - العراق على مختلف مستوياتهم الاجتماعية ومن كلا الجنسين. ج- المجال الزمني: إن المدة التي إستغرقتها عملية توزيع الإستمارات وجمع البيانات الميدانية من وحدات عينة البحث وتفريغها وتحليلها هي من 2015/8/1ولغاية 2015/10/10. 5.2.4 الوسائل الاحصائية المستخدمة في البحث: يؤدي

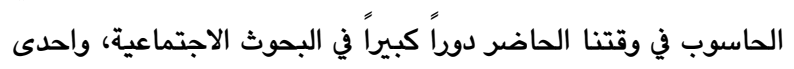
البرامج التي أستعان الباحث بها هي الحقيبة الاحصائية للعلوم الاجتماعية (SpSS) لاكمال اجراءات البحث وتحليل نتائجها والوقوف هي على أهداف البحث، وقد استخدم الباحث، في هذا البحث (التكرارات، نسبة المئوية الوسط الحسابي ، الانحرافالمعياري. 5. الجانب الميداني للبحث

يقوم الباحث هنا بعرض وتحليل الذصائص العامة لأفراد عينة البحث، انطلاقا من ان البيانات الشخصية تشكل متغيرات ذات دلالة يمكن ان تؤثر على استجابات المجحوثين، وتساعدنا على توضيح وتفسير بعض المواقف وآراء المبحوثين حول عنوان البحث. 1.5

1.1 .5

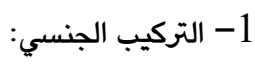
جدول رقم(1): يوضح جنس المبحوثين

\begin{tabular}{|c|c|c|}
\hline النسبة المئوية ٪٪ & العدد & الجنس \\
\hline$\% 73.38$ & 204 & ذكر \\
\hline$\% 26.62$ & 74 & انثى \\
\hline$\% 100$ & 278 & المجموع \\
\hline
\end{tabular}

$$
\text { 5- أ.م.د. بدرخان مصطفى - جامعة كوية- علم النفس. }
$$

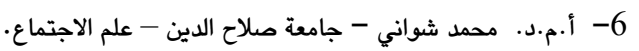

2.2 .4 عينة البحث: Research Sample

لذا قام الباحث بتحديد عينة أو نموذج مجتمع البحث وقد بلغ حجم عينـة البحث (300) فرداً من الـذكور والإنـاث من ســـــان اقليم

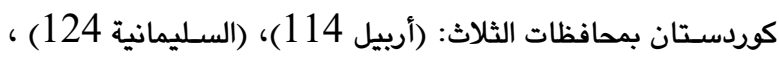

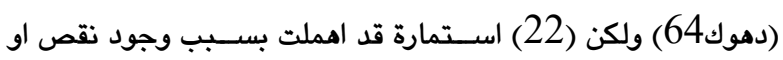
شطب فيها. وان عينة البحث التي يتم ا ستخدامها هي (العينة الق صدية) وهي نوع من العينات غير الاحتمالية تســــخدم في البحوث الاجتماءية عادة عندما يكون مجتمع غير محدد المعالم أو لا يمكن اعداد قائمة متكاملة باسماء الوحدات التي تكونه ويتم اختيار الوحدات العشـوائية بطريقة

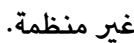
3.2.4 أدوات جمع البيانات: ويقصد بتصميم أداة البحث، الاجراءات والخطوات المنهجية المتبعة في اعداد الوسيلة التي بواسطتها يتم جمع البيانات المتعلقة بموضوع البحث من وحدات عينة البحث.

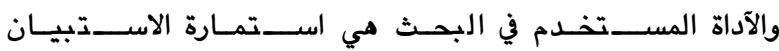
Interview والمقابلة Questionnaire أ- الاستمارة الاستبيانيةفي الوقت الحاضر تعتبر الاستبانة وسيلة معتادة ومنتشــرة في البحوث الاجتماعية، فهي الوســيلة المباشــرة والمؤثرة في جمع المعلومات والبيانات، من أجل الإجابة عليها ولجمع

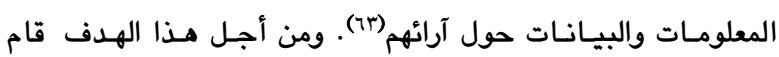
الباحث بإعداد إستمارة استطلاعية. تضــمنت الاسـتمارة الاسـتبيانية من عدة أسـئلة عددما (44) عن

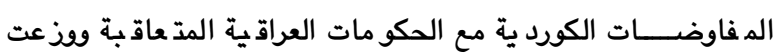
الاستمارة حسب محاور او اهداف البحث الى اسباب داخلية واسباب الخارجية وللتأكد من جودة الاستمارة قام الباحث بتوزيعها على عدد من المختصين والمحكمين في اختصاصات علم الاجتماع وعلم النفس والقانون والسـياسـية(*). واعتماداً على آراءهم ملاحظاتهم بشــأن الأسئلة الاستبيانية ، فقد حذفت بعضاً منها وأعدت صياغة بعضهاً الآخر، كما اجريت بعض التعديلات على بعضـــهاً آخر ودمج عدة اسئلة مع بعضها، وعندما تم احتساب المعدل العام لذسب موافقة الخبراء على الاستمارة التي وافقوا عليها تبين أن معدل هذه الذسب

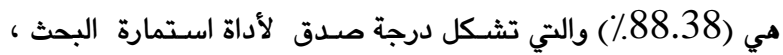
ومن اجل التأكد منها قام الباحث بتوزيع اسـتمارة على (25) فرداً من كلا الجنسـين من المجتمع البحث من اجل اســخراج ثباة الاداة

\footnotetext{
(*) أ. 1. أ.د. رزكار قادر محمد- جامعة صلاح الدين - قانون والسياسة.

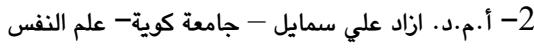

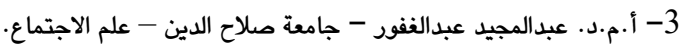
4- أ.م.د. عبدالله خورشيد جامعة صلاح الدين - علم الاجتماع.
} 
يعتبر مســـتوى الدخل من مقومات الحياة بحيث تنعكس اثاره على

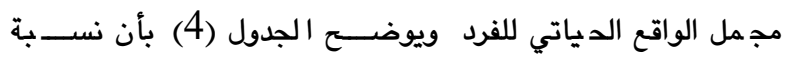

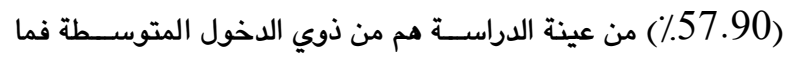

فوق. 5

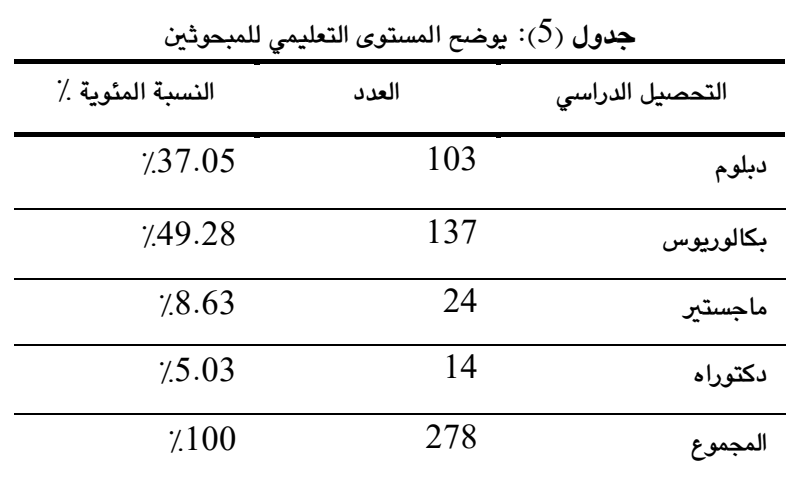

إن للتعليم أو المؤهل العلمي أهمية بالغة، إذ قد يؤثر في مســتوى

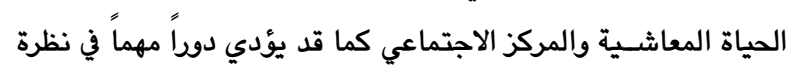

الافراد الى البيئة الاجتماعية التي يعيشون فيها.

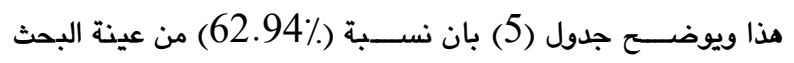
حصــلوا على شـــهادة جامعية وفوق الجامعية ومذا قد يؤثر على لى

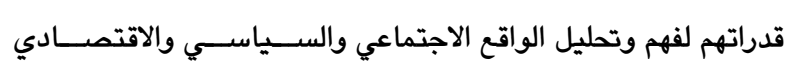

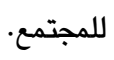
6 جدول (6): يوضح إنتماء المبوحثين الى حزب سياسي

\begin{tabular}{|c|c|c|}
\hline النسبة المئوية ٪ & العدد & نمط الاجابة \\
\hline$\% 45.32$ & 126 & نعم \\
\hline$\% 54.68$ & 152 & لا \\
\hline$\% 100$ & 278 & المجموع \\
\hline
\end{tabular}

ينعكس الموقف السيا سي للفرد على موقفه ازاء العديد من القضايا التي ترتبط بحياته الاجتماعية والسـياسـية خاصـــة ضــمن الفئات التعليمية حيث تعتبر هذه الفئات مهمة و مؤثرة بشكل مباشر او غير بريك مباشر على الواقع السياسي والاجتماعي الذي يعيشون فيه.

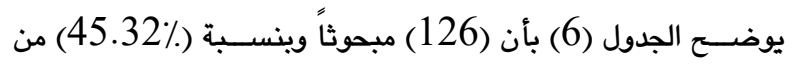

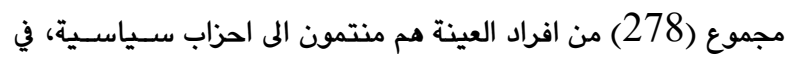
حين نجد (152) من المبحوثين وينسبة (.54.68\%) هم غير منير منتمين

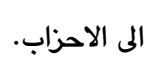

يتبين من بيانات الجدول اعلاه بأن نسـبة المبحوثين الذكور أكبر من نســبة المبحوثين الاناث في مجموع العينة البالغ (278) مبحوثاً وان بان مذا الاختلاف في اختيار المبحوثين يعود الى أن الذكور في العادة أكثر امتماماً بالسياسة والعمل السياسي من الاناث، هذا من جهة ومن جهة اخرى قد تكون هناك أ سباباً موضوعية وذاتية تتعلق بكلا الجذسين من خلال الرؤية والوعي والنضــج والثقافة السـياسـية في نظرتهم الى الامور السياسية ومدى مشاركتهم في الحياة السياسية. 2 جدول رقم (2): يوضح عمر المبحوثين

\begin{tabular}{|c|c|c|}
\hline النسبة المئوية ٪\% & العدد العد & فئات العمر \\
\hline صفر & صفر & 25-34 سنة \\
\hline$\% 64.75$ & 180 & 35-44 سنة \\
\hline$\% 27.33$ & 76 & 45-54 سنة \\
\hline$\% 7.91$ & 22 & 55 سنة فما فوق \\
\hline$\% 100$ & 278 & المجموع \\
\hline
\end{tabular}

توضـــــ بيانات الجدول رقم (2) اعمار عينة البحث التي تقع بين (35) سنة الى (64) سنة متو سط الدسابي (43.81) ويانحراف

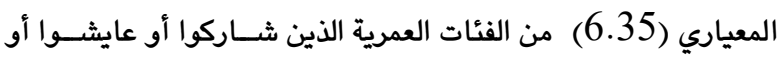
تابعوا الثورة الكوردية بمراحلها المختلفة وعندهم ؤية حول القضـايا المختلفة للشعب الكوردي. 3 محل الإقامة جدول (3): يوضح محل الاقامة للمبحوثين

\begin{tabular}{|c|c|c|}
\hline النسبة المئوية ٪٪ & العدد & محل الاقامة \\
\hline$\% 41.007$ & 114 & اربيل \\
\hline$\% 35.97$ & 100 & سليمانية \\
\hline$\% 23.02$ & 64 & دهوك \\
\hline$\% 100$ & 278 & المجموع \\
\hline
\end{tabular}

يظهر من بيانات جدول (3) بأن عينة المبحوثين موزعة على جميع محافظات الاقليم كل حسب ذسبة السكان فيه وذلك لما يؤدي محل إقامة المبحوثين من دور مام في الاستجابات حول القضايا الموجودة دسيه في المجتمع. 4 المستوى الاقتصادي: جدول (4): يوضح مستوى الدخل للمبحوثين

\begin{tabular}{|c|c|c|}
\hline النسبة المئوية ٪٪ & 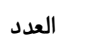 & مستوى الدخل \\
\hline$\% 42.08$ & 117 & 300-799 الف دينار \\
\hline$\% 44.96$ & 125 & 800-1299 الف دينار \\
\hline \multirow[t]{2}{*}{$\% 12.94$} & 36 & 1300- 1799 الف دينـار فمـا \\
\hline & & 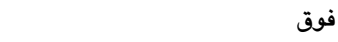 \\
\hline$\% 100$ & 278 & المجموع \\
\hline
\end{tabular}


سـبب ذلك الى اخلاق وعادات والتقاليد الاصـيلة للشـعب الكوردي في تعاملهم بصدق حتى مع اعدائهم مما أثر على عدم إمكانية حصولهم على ما كانوا يريدون الحصول عليه. جدول (9): يوضح عدم تماسك الجبهة الداخلية والتنسيق بين القيادات الكوردية

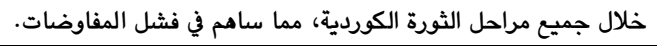

\begin{tabular}{|c|c|c|}
\hline النسبة المئوية ٪ & تكرارات & 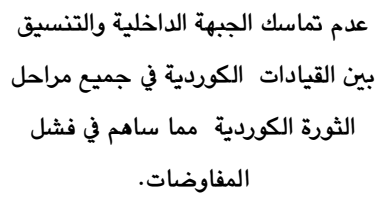 \\
\hline$\% 42.80$ & 119 & أوافق تماماً \\
\hline$\% 31.65$ & 88 & أوافق \\
\hline$\% 9.71$ & 27 & لا راي لي \\
\hline$\% 12.23$ & 34 & لا أوافق \\
\hline$\% 3.59$ & 10 & لا أوافق بشدة \\
\hline$\% 100$ & 278 & المجموع \\
\hline
\end{tabular}

ذستنتج من مؤشرات الجدول (9) بأن بذسبة (74.45\%) من أفراد

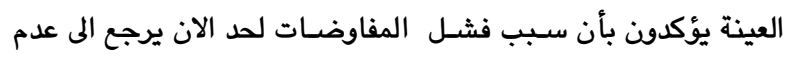

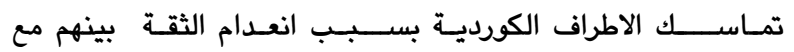

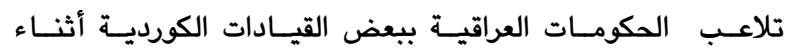

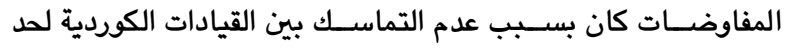

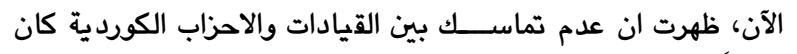
سبياً في عدم حصول الشعب الكوردي مما كانت يريد حصول عليه

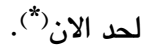
جدول (10): يوضح تسرع القيادات الكوردية في ارسال برقيات التهاني وابداء

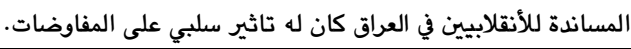

\begin{tabular}{|c|c|c|}
\hline النسبة المئوية ٪ & ت تكرارات & 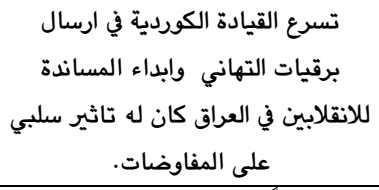 \\
\hline$\% 25.53$ & 71 & 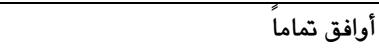 \\
\hline$\% 23.74$ & 66 & أوافق \\
\hline$\% 22.66$ & 63 & لا راي لي \\
\hline$\% 20.50$ & 57 & لا أوافق \\
\hline$\% 7.55$ & 21 & لا أوافق بشدة \\
\hline$\% 100$ & 278 & المجموع \\
\hline
\end{tabular}

تشــير بيانات الجدول (10) ان نســبة (49.27\%) من افراد العينة

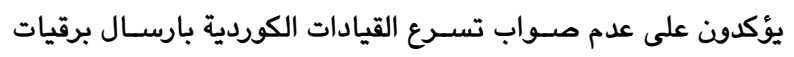
التهنئة وابداء المساندة للانقلابيين في العراق، ومذا قد يدمئ يرجع الى شعور

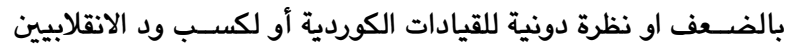

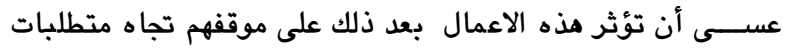

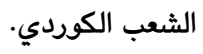

(") لقاء مع استاذ عبدالرحمن صديق، سياسي ومثقف وكاتب ،وزير بيئة العراقي السابق، تمت مقابلة في اربيل 2015/10/30
1.1 .5

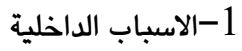

جدول (7): يوضع نسبة عدم وجود التوانن والمتخصصين بين الوفد الكوردي وفف الحكومات العراقية من المفاوضات

\begin{tabular}{|c|c|c|}
\hline النسبة المئوية ٪\% & تكرارات & 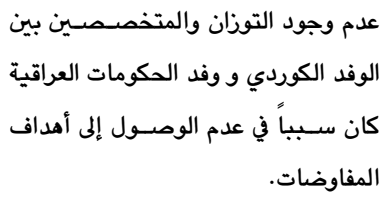 \\
\hline$\% 29.13$ & 81 & أوافق تماماً \\
\hline$\% 45.32$ & 126 & أوافق \\
\hline$\% 8.63$ & 24 & لا راي لي \\
\hline$\% 14.02$ & 39 & لا أوافق \\
\hline$\% 8.87$ & 8 & لا أوافق بشدة \\
\hline$\% 100$ & 278 & المجموع \\
\hline
\end{tabular}

يو أحس الجدول (7) بأن ذسبة (74.45\%) من عينة البحث يؤكدون بأن أحد أســباب فشــل المفاوضــات أو عدم تدقيق ما تسـعى اليه الثورة الكوردية كان مو عدم وجود متخصصين في شؤون المفاوضات من الكورد، وهذا قد يرجع الى عدم قدرة الاحزاب الكوردية انذاك على

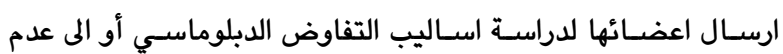
وجود مجال لذلك من جانب آخر، مما لاثــــك ان عدم وجود التوزان بين الوفـد الكوردي والوفود الحكومـات العراقيـة في جميع الجوانب

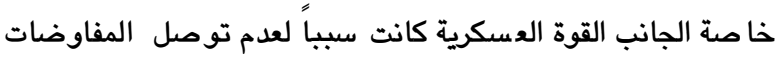

$$
\text { الى نتيجة (*). }
$$

جدول (8): يوضح أن عدم التزام قيادات الثورات الكوردية بالمناورات والتكتيكات

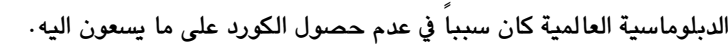

\begin{tabular}{|c|c|c|}
\hline النسبة المئوية ٪ & تكرارات & 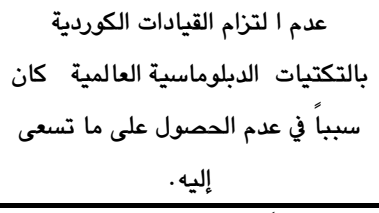 \\
\hline$\% 28.77$ & 80 & أوافق تماماً \\
\hline$\% 32.37$ & 90 & أوافق \\
\hline$\% 15.46$ & 43 & لا راي لي \\
\hline$\% 18.34$ & 51 & لا أوافق \\
\hline$\% 4.03$ & 14 & لا أوافق بشدة \\
\hline$\% 100$ & 278 & المجموع \\
\hline
\end{tabular}

نلاحظ من معطيات الجدول (8) بأن اكثر من نصـــف المبحوثين بنسـبة (61.14\%) يؤكدوف عدم معرفة أو عدم التزام القيادات الكوردية بالمناورات والتكتيكات الدبلوماســية العالية التي كان بودان المفاوضـين غير الكورد يمارسـونها اثناء عملية التفاوض وقد يرجع

(*) لقاء مع د. فرست صوفي، عضو برلمان اقليم كوردستان 2014-2018، قدائمة

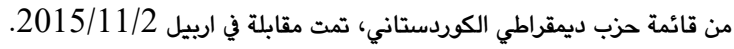


جدول (13): يوضح ان وجود الاختلاف وتقاطع المصالح للقيادات الكوردية كان سبباً في فشل المفاوضات بين الثورة الكوردية والحكومات العراقية.

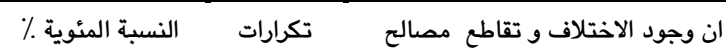
القيادات الكوردية كان سبياً في فشل ودافل المفاوضات الكوردية مع الحكومات

\begin{tabular}{|c|c|c|}
\hline & \multicolumn{2}{|c|}{ العراقية المتعاقبة. } \\
\hline$\% 48.56$ & 135 & أوافق تماماً \\
\hline$\% 31.65$ & 88 & أوافق \\
\hline$\% 8.27$ & 23 & لا راي لي \\
\hline$\% 8.99$ & 25 & لا أوافق \\
\hline$\% 2.58$ & 7 & لا أوافق بشدة \\
\hline$\% 100$ & 278 & المجموع \\
\hline
\end{tabular}

اظهرت بيانات جدول (13) بأن نســبة (80.21\%) من المبحوثين يؤكدون على ان وجود اختلاف وتقاطع المصـالح بين قيادات الثورة

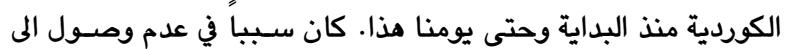
ماكان يريده الشـــب الكوردي وهذا قد يرجع الى عدم اســـقلالية الثورة الكوردية والقيادات في ثورتهم اذ كل حزب تابع لقوى دولية تختلف مصلحتها من طرف آخر.

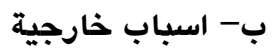
جدول (14): يوضح ان عدم التزام الحكومات العراقية المتعاقبة ببرامج

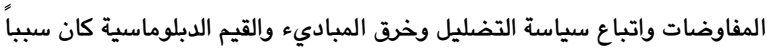
لفشل المفاوضات.

\begin{tabular}{|c|c|c|}
\hline النسبة المئوية ٪٪ & تكرارات & 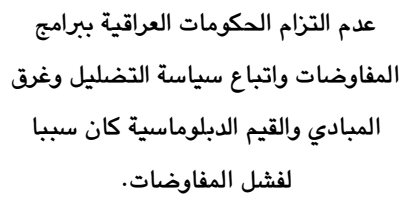 \\
\hline$\% 38.12$ & 106 & أوافق تماماً \\
\hline$\% 40.64$ & 113 & أوافق \\
\hline$\% 8.99$ & 25 & لا راي لي \\
\hline$\% 8.63$ & 24 & لا أوافق \\
\hline$\% 3.59$ & 10 & لا أوافق بشدة \\
\hline$\% 100$ & 278 & المجموع \\
\hline
\end{tabular}

نلاحظ في جدول (14) ان اكثر من (78.76\%) من افراد العينة يرى بأن فشـــلـل المفاوضــــات بين الثورات الكوردية والحكومات العراقية المتعاقبة منذ 1921- 1992 ولريما لحد الآن يرجع الى عدم التزام الحكومات العراقية ببرامج المفاوضــــات من جانب، ومن جانب آخر يرجع الى اتباع سياسة التضليل وخرق المباديء والقيم الدبلوماسية.
جدول (11): يوضح أن عدم اعتماد القيادات الكوردية على المثقفين والمتنورين

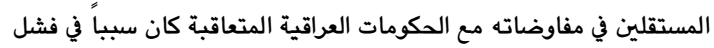
المفاوضات.

\begin{tabular}{|c|c|c|}
\hline النسبة المئوية ٪٪ & تكرارات & 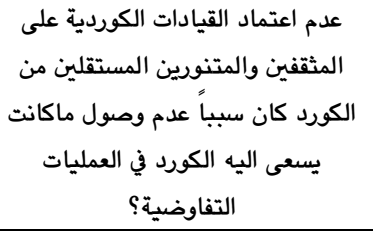 \\
\hline$\% 41$ & 114 & أوافق تماماً \\
\hline$\% 36.39$ & 102 & أوافق \\
\hline$\% 10.79$ & 30 & لا راي لي \\
\hline$\% 8.99$ & 25 & لا أوافق \\
\hline$\% 2.51$ & 7 & لا أوافق بشدة \\
\hline$\% 100$ & 278 & المجموع \\
\hline
\end{tabular}

يوضح جدول (13) بأن نسبة (77.39\%) من المبحوثين تؤكد على عدم اعتماد واســــفادة القيادات الكورد ية من المثقفين المتنورين

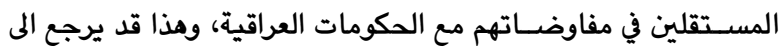

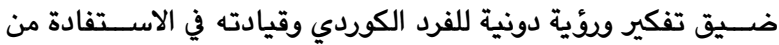

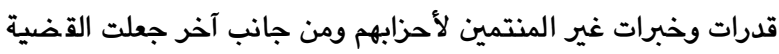

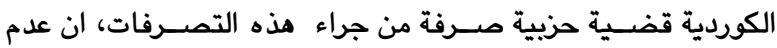
امتمام القيادات والاحزاب السـياسـية الكوردية على مر تاريخ لم يهتم

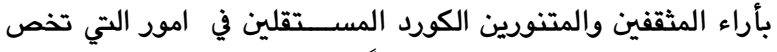

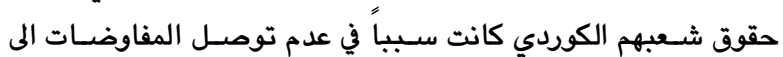

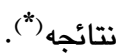

جدول (12): يوضح مدى ما كانت مفاوضات القيادات الكوردية ذات صبغة شخصية أكثر من كونها ذات صبغة رسمية.

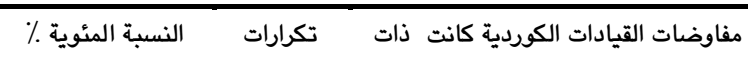
صيغة شخصية اكثر من كونها ذات

\begin{tabular}{|c|c|c|}
\hline & & \\
\hline$\% 34.53$ & 96 & أوافق تماماً \\
\hline$\% 31.65$ & 88 & أوافق \\
\hline$\% 13.66$ & 38 & لا راي لي \\
\hline$\% 13.66$ & 38 & لا أوافق \\
\hline$\% 6.47$ & 18 & لا أوافق بشدة \\
\hline$\% 100$ & 278 & المجموع \\
\hline
\end{tabular}

تدل بيانات جدول (12) بأن نســبة (66.18\%) من عينة البحث

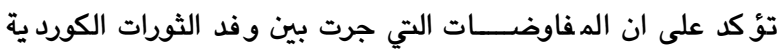
والحكومات العراقية المتعاقبة كانت تطغى عليها صــبغة ثــخصـية أكثر من كونها ذات صبغة رسمية، مما كانت سبياً لفشل المفاوضات وعدم حصوله على حقوقه. 
جدول (17): يوضح عدم امتلاك الحكومات العراقية القرار النهائي في حل قضية

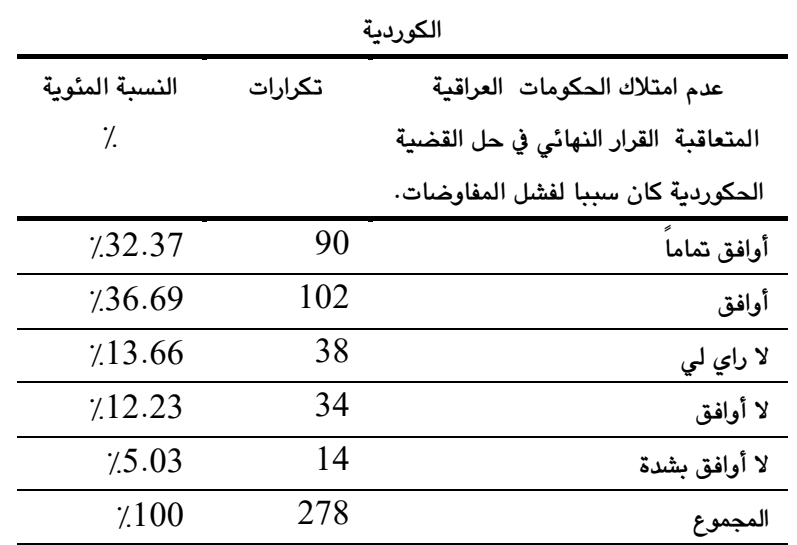

نلاحظ من الجدول (17) بأن بنسـبة (69.06\%) من افراد عينة

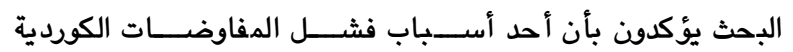
والحكو مات العراقية يرجع الى عدم إمتلاك الحكو مة العراقية القرار النهائي في حل المشــكلة الكوردية وذلك لتوزيع نفوذ الدول الكبرى في المنطقة حيث كانت دول المنطقة موزعين بين المعسكرين الراسمالي

والاثتراكي.. الجدول (18): يوضح اهمية تكون ان المفاوضات تحت اشراف المنظمات

\begin{tabular}{|c|c|c|}
\hline \multicolumn{3}{|c|}{ الدولية } \\
\hline $\begin{array}{c}\text { النسبة المئوية } \\
\text { \% }\end{array}$ & تكرارات & 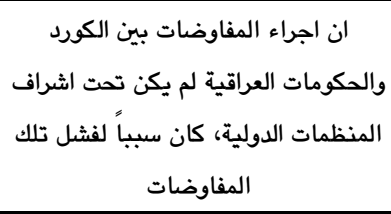 \\
\hline$\% 34.89$ & 97 & أوافق تماماً \\
\hline$\% 33.81$ & 94 & أوافق \\
\hline$\% 13.3$ & 37 & لا راي لي \\
\hline$\% 13.3$ & 37 & لا أوافق \\
\hline$\% 4.67$ & 13 & لا أوافق بشدة \\
\hline$\% 100$ & 278 & المجموع \\
\hline
\end{tabular}

يوضـح جدول (18) أن بنسـبة (68.70 \%) من أفراد العينة يرون ان من أسـباب فشـل المفاوضــات بين الحكومات العراقية والقيادات

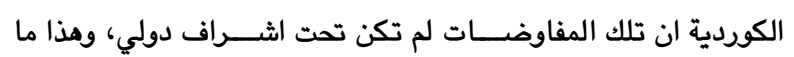
يؤكده نتائج كل المفاوضات الذي جرت بينهم. جدول (19): يوضح ان ضعف أو انعدام التواصل بين قيادة الحركة التحرية

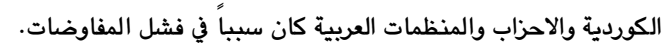

\begin{tabular}{|c|c|c|}
\hline النسبة المئوية & تكرارات & ضالحفة او انعدام التواصل بين قيادة \\
\hline$\% 46.04$ & 128 & أوافق تماماً \\
\hline$\% 30.93$ & 86 & أوافق \\
\hline$\% 11.51$ & 32 & لا راي لي \\
\hline$\% 8.63$ & 24 & لا أوافق \\
\hline$\% 2.78$ & 8 & لا أوافق بشدة \\
\hline$\% 100$ & 278 & المجموع \\
\hline
\end{tabular}

الجدول (15): يوضح أن تغير انظمة الحكم في العراق لم يُؤثر على النظرة

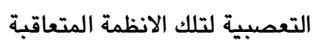

\begin{tabular}{|c|c|c|}
\hline النسبة المئوية ٪ & تكرارات & 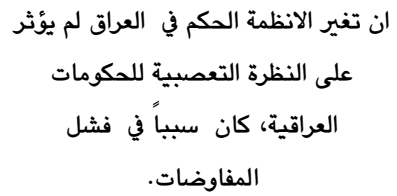 \\
\hline$\% 55.39$ & 154 & أوافق تماماً \\
\hline$\% 32.73$ & 91 & أوافق \\
\hline$\% 6.83$ & 19 & لا راي لي \\
\hline$\% 2.87$ & 8 & لا أوافق \\
\hline$\% 2.15$ & 6 & لا أوافق بشدة \\
\hline$\% 100$ & 278 & المجموع \\
\hline
\end{tabular}

توضسع بيانات جدول (15) ، بان نسبة (88.12) من أفراد عينة

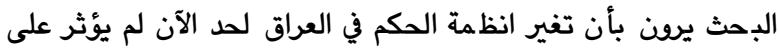

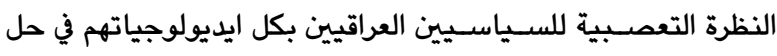

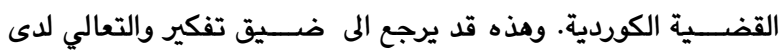
القيادات العربية اتجاه القوميات اخرى في بلدانهم. جدول (16): يوضح انعدام الرغبة الصادقة لدى الحكومات العراقية لحل القضية الكوردية

\begin{tabular}{|c|c|c|}
\hline النسبة المئوية ٪٪ & تكرارات & 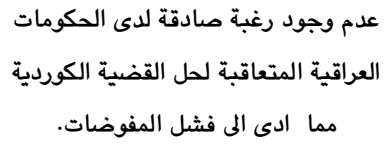 \\
\hline$\% 46.76$ & 130 & أوافق تماماً \\
\hline$\% 31.01$ & 89 & أوافق \\
\hline$\% 13.30$ & 37 & لا راي لي \\
\hline$\% 6.11$ & 17 & لا أوافق \\
\hline$\% 1.79$ & 5 & لا أوافق بشدة \\
\hline$\% 100$ & 278 & المجموع \\
\hline
\end{tabular}

تشير بيانات الجدول (16) الى ان (\% 77.77) من أفراد عينة البحث يرون ان عدم وجود رغبة صـــادقة لدى الحكومات العراقية المتعاقبة لحل القضية الكوردية في العراق كان سبباً في فشل المفاوضات وهذا

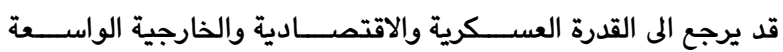
للحكومات العراقية مقارنة بضــــف الثورة الكوردية في هذا الجوانب، ومن جانب آخر قد يرجع الى عدم اهتمام الدول العظمى في تلك الحقبة بمساندة ثورات دول العالم الثالث قاطبة. 
5- تبين نتائج البحث بأن (1\% 80.21) من المبحوثين يؤكدون على

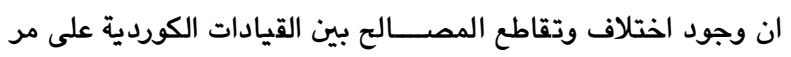
تأريخ الحركة التحرية الكوردية كان أحد الاسباب الرئيسية في فشل بئ المفاوضات. 6- أظهرت الذتائج بأن (78.76) من المبحوثين يؤكدون على ان سـبب فشـل المفاوضــات يرجع الى اتباع سـياســة تضــليل وخرق المباديء والقيم الدبلوماسية من قبل الحكومات العراقية. 7- إثــارت نتائج البحث بأن (.88.12) من المبحوثين اكدوا على منى أن تغير انظمة الحكم في العراق لم يؤثر على رؤية ومواقف الحكومات العراقية في حل القضية الكوردية عن طريق المفاوضات. 8- تبين ان (77.77\%) من المبحوثين يؤكدون على ان عدم وجود

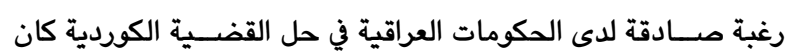
سبياً في فشل المفاوضات. 9- أظهرت النتـائج بـأن (76.97\%) من المبحوثين يؤكدون بـأن ضـــف التواصــلـل والعلاقة بين القيادات الكوردية وقيادات الاحزاب والمنظمات العربية كان أحد أسباب فشل المفاوضات. 10- تبين البحث (87.40\%) من المبحوثين يؤكدون بأن أحد

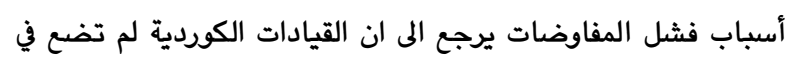

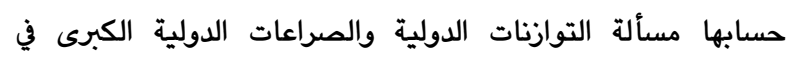
المنطقة.

2.6 المقترحات والتوصيات: اسـتكمالاً لنتائج البحث الحالي وتطويراً لها، يوصـي الباحث ويقترح عدداً من التوصيات والمقترحات أهمها:

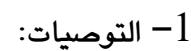

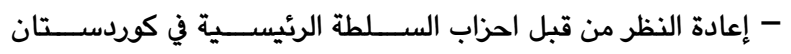

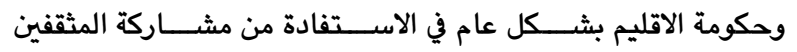

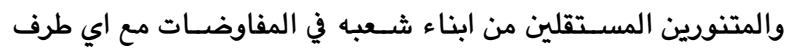
آخر. - على الاحزاب الكورد، والســــــطة والحكومة في الاقليم ان تهتم أو تضع المصلحة العامة للشعب والوطن في كوردستان فوق كل المصالح

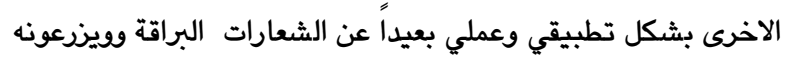
في فكر وعقلية اعضائهم.

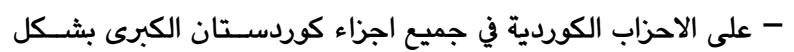

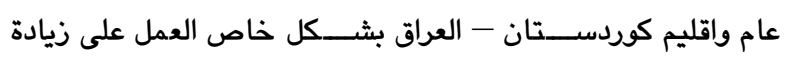

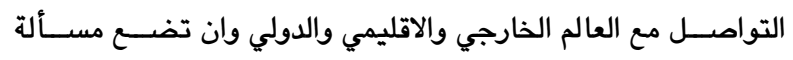
التوازنات الدولية وصراع الدول الكبرى في المنطقة في حسبانها.

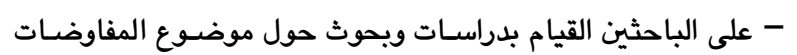

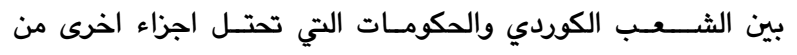

يبين الجدول (19) بان نســبة (76.97\%) من افراد عينة البحث

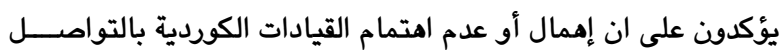

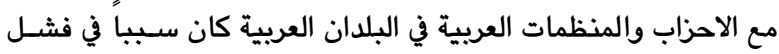
المفاوضات بين الثورة الكوردية والحكومات العراقية المتعاقبة. جدول (20): يوضح بأن القيادات الكوردية لم تضع في حسبانها في مسيرتها النضالية، مسألة التوازنات الدولية وصراع الدول الكبرى.

\begin{tabular}{|c|c|c|}
\hline $\begin{array}{c}\text { النسبة المئوية } \\
\text { \% }\end{array}$ & تكرارات & 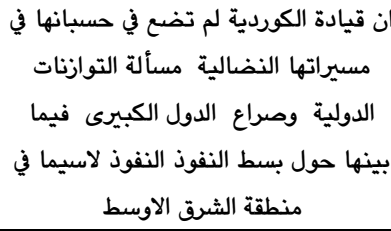 \\
\hline$\% 58.63$ & 163 & أوافق تماماً \\
\hline$\% 28.77$ & 83 & أوافق \\
\hline$\% 3.95$ & 11 & لا راي لي \\
\hline$\% 4.67$ & 13 & لا أوافق \\
\hline$\% 3.59$ & 10 & لا أوافق بشدة \\
\hline$\% 100$ & 278 & لمجموع \\
\hline
\end{tabular}

تشـــير بيانات جدول (20) بأن نســبة (87.40) من افراد عينة البحث يؤكدون بأن عدم نجاح الثورات الكوردية منذ عام 1921 الى لى

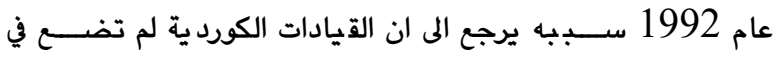

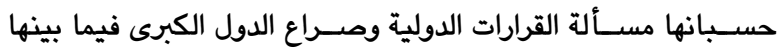

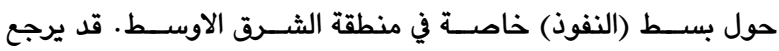

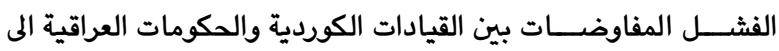

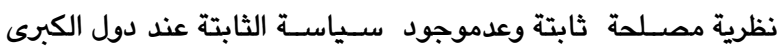
مذا من جانب ومن جانب الاخر الى عدم اهتمام القيادات الكوردية

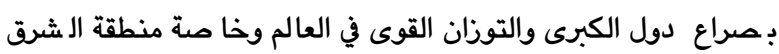
الاوسط (*). 6. اتمة البحث

1.6 1- إتضح أن أغلبية أعمار عينة المبحوثين تتراوح، بين (40-35) سنة وينسبة (64.75\%). 2- تبين ان (74.45\%) من المبحوثين يؤكدون على أن عدم وجود (04) (أن

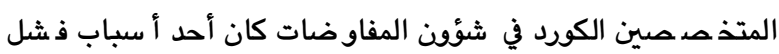
تلك المفاوضات. 3- اظهرت النتائج بان نســبة (74.45\%) من المبحوثين يؤكدون على أن عدم وجود تماسـك بين القيادات الكوردية كان سـبياً في عدم حصول الشعب الكوردي على حقوقه. 4- أظهرت النتائجبأن (.77.39\%) من المبحوثين يؤكدون على أن عدم اعتماد القيادات الكوردية في مفاوضـــاتهم مع الحكومات العراقية المتعاقبة على المثقفين والمتنورين المستقلين من أبناء شعبهم كان أحد أسباب فشل تلك المفاوضات.

(*) لقاء مع استاذ محسن دزيي من القادة البارزين في الحزب ديمقراطي كوردستانى، تم المقابلة في اربيل 2015/11/3. 
24. مشام الشاوي، الوجيو في فن التفاوض ، ط1، مطبعة شفيق، بغداد،

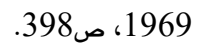

25. محمد عبدالغني حسن هلال، مهارات التفاوض، رياض ، ب. صنة سنة طع، دار

قرطبة للنشر والتوزيع، صبد1 181-182.

26. ثابت عبدالرحمن إدريس، التفاوض استراتيجيات وتكنيكات ومهارات تطبيق،

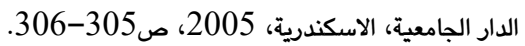

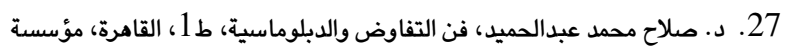

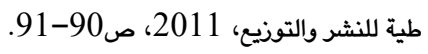

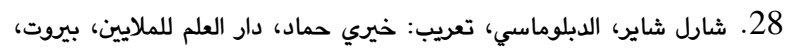

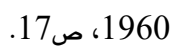

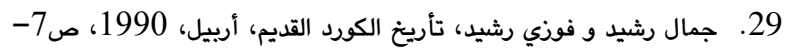

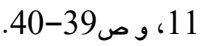

30. كمال مظهر أحمد، كوردستان في سنوات الحرب العالمية الأولى، التحقيق

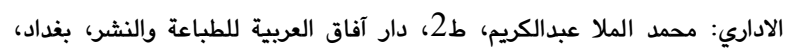
1994، ص201

31. شيخ لطيف الحفيد، ياداشت ساغ كردنةوةى كمال نوري معروف، ج1، بـ ب.ش،

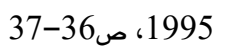

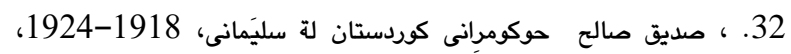

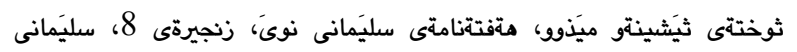

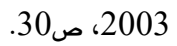

33. كمال مظهر أحمد المصدر السابق، ص3003، م2324-324.

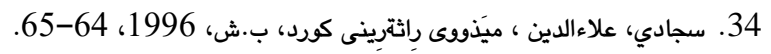

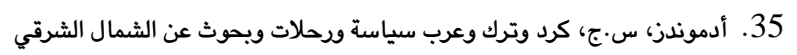

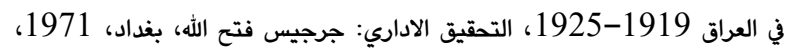

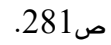
36. المصدر نفسه، 285.

37. حمدي، وليد، الكورد وكوردستان في الوثائق البريطانية، لندن، 1991،

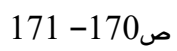
38. صالح، صديق، حوكومرانى كوردستان لة سليَمانى، 1918-1924، دئَ

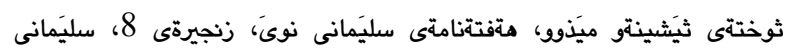
2003، ـ203-83

39. عبدالعزيز ياملكي،، كاشف القناع عن بعض الوقائع العراقية (مذكرات)، ج1، ،

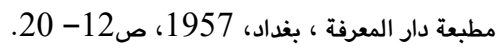

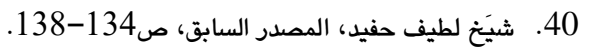

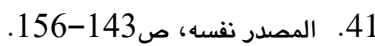

42. محمد عبدالله كاكةسور، الدود السياسي والثقافي للضباط الكورد في الحركة

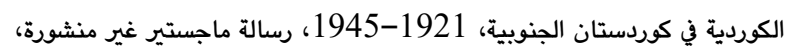

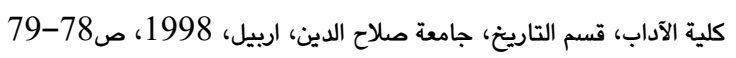

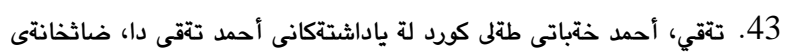

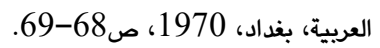

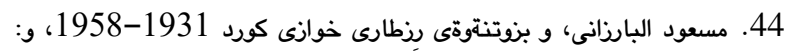

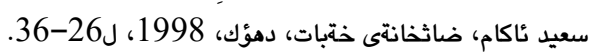

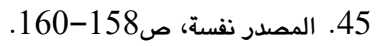

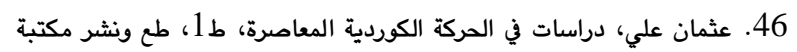
التفسير، أربيل، 46 2003، عثمان، دراسات في التركة

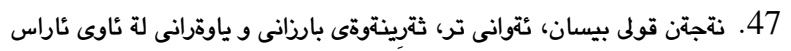

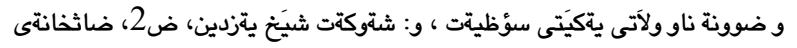

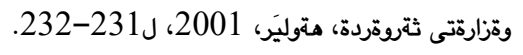

كوردسـتان بشــكل أعمق واوســع لتوضـيح مخاطرها على مسـتقبل

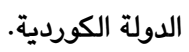

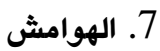

1. Kennedy, 6.6 Ben Son, J-and Mcmilan,J, Managing Ne gto I ation- London: H4tch in Son Business Books, Limited (1987), p15 .

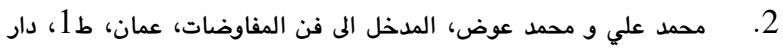

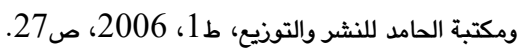
3. د. حافظ علوان حمادي، المدخل إلى علم السياسة، مطبعة جامعة بغداد،

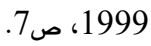

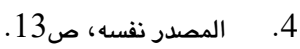

5. د. حسين سيد سليمان، مباديء العلوم السياسية، ط1، الوكالة اليمنية

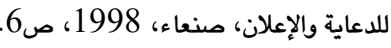

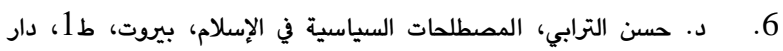

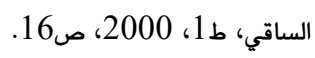

7. السيد صدرالدين القبانجي، علم السياسة، تجديد من وجهة نظر إسلامية،

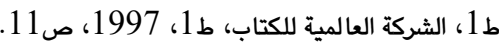

Pareto, Traitede sociologie generale Droz, Paris. 8

1968, p.72,5, cite par R-gschwar tzenberg, op. cit. p. 217.

9. د.عبدالمنعم المشاط، قاموس المفاهيم السياسية، ط1، مركز القاهرة

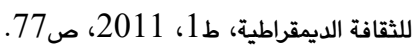

10. كاروس البرتو، الثقافة وسلوك النخب في امريكا اللاتينية، ت.أ.د. قيس صيس

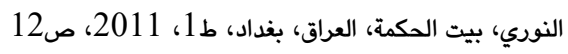

11. ريموند آرون، أفيون المثقفين، ت: عادل زيتوني، منشورات، المبات المكتبة الأهلية،

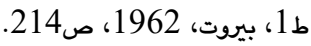

12. ناجي معروف، اصالة الحضارة العربية، بيروت، ط1، دار دار المعارف، 1979،

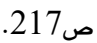

13. أدوارد سعيد، نيشانةكانى رؤشنبي،، وةرطيَرِانى لة فارسيةوة: دواد رسولي

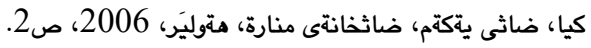

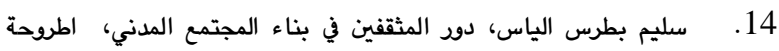

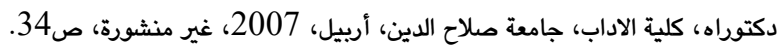

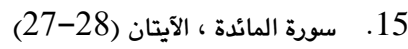

16. شوقي ناجي و عباس غالي أبو التمن، التفاوض، مهارة واستراتيجية-

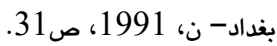

17. محمد حافظ غانم، مباديء القانون الدولي، القاهرة، مطبعة الحرمين، 1967،

ص56

18. عزالدين فودة، ما الدبلوماسية، القاهرة، المكتبة الثقافية، د.ت.ص2609.

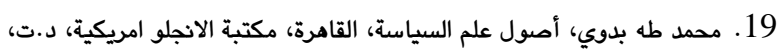

ص 282

20. ناجي معروف، آصالة الحضارة العربية، بيروت،ط1، دار المعارف، 1979،

ص43

21. محمد علي ومحمد عوض، المدخل الى المفاوضات، ط1، مكتبة الحامد

للنشر، عمان، ص3..

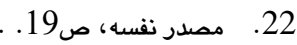

23. رانية خوام، السياسية عند العرب، لندن، دار الساقي، 1988، ص5 .

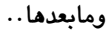


7. الترابي، حسن ، المصطلحات السياسية في الإسلام، بيروت، ط1، دار الساقي، ط $2000 ،$

8. الحفيد، شيخ لطيف، ياداشت ساغ كردنةوةى كمال نوري معروف، ج1، ب.ش، 1995.

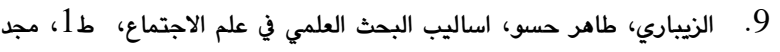

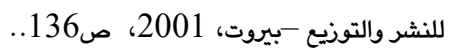
10. الشاوي، هشام، الوجيز في فن التفاوض ، ط1، طب، مطبعة شفيق، بغداد، .1969

11. الطالباني، جلال، كوردستان والحركة القومية الكوردية، مطبعة الجمهورية،

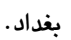
12. القبانجي، السيد صدرالدين ، علم السياسة، تجديد من وجهة نظر إسلامية، ط1، الشركة العالمية للكتاب، ط1، الفيد مدرالن ، 1997. 13. المشاط ، عبدالمنعم ، قاموس المفاهيم السياسية، ط1 19 19 مركز القاهرة للثقافة الديمقراطية، ط1، 13 المشاط، 2011. 14. الموصلي، منذر، القضية الكوردية في العراق، البعث والأكراد، دار المختار، دمشق، 2000.

15. الياس، سليم بطرس ، دود المثقفين في بناء المجتمع المدني، اطروحة

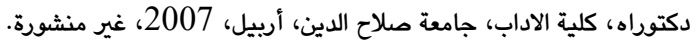

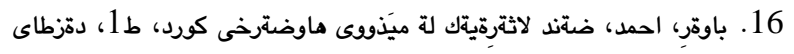

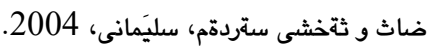
17. بدوي، محمد طه، أصول علم السياسة، القاهرة، مكتبة الانجلو امريكية، د.ت.

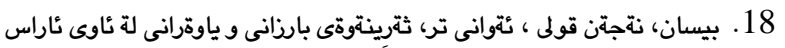

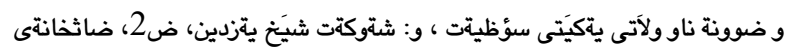

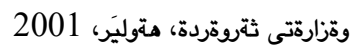

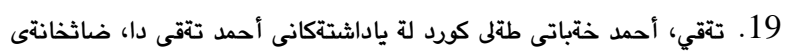

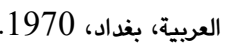

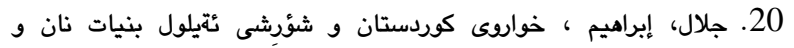

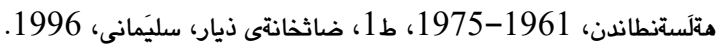

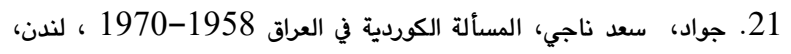
1990، ص78. 22. حمادي، حافظ علوان ، المدخل إلى علم السياسة، مطبعة جامعة بغداد، .1999

23. حمدي، وليد، الكورد وكوردستان في الوثائق البريطانية، لندن، 1991.

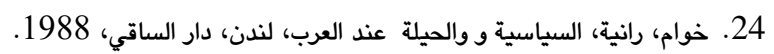

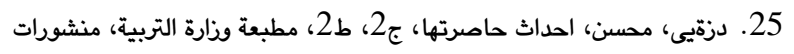
دار اراس، اربيل. 26. دويدري، رجاء وجيه، البحث العلمي (أساسيات النظرية والممارسة العلمية) دار الفكر، بيرت، 2008 2008، دوبدي،

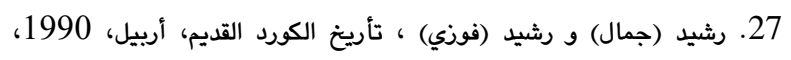

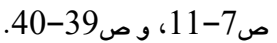

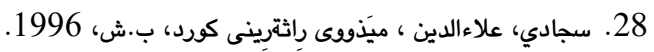

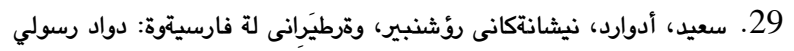

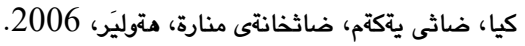

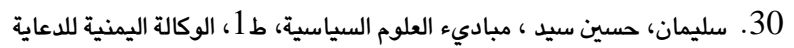

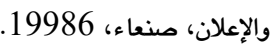
31. شاير، شارل، الدبلوماسي، تعريب: خيري حماد، دار العلم للملايين، بيروت، .1960

$$
\begin{aligned}
& \text { 48. مسعود البارزاني، المصدر السابق، ص212-214. }
\end{aligned}
$$

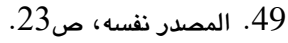

50. منذر الموصلي، القضية الكوردية في العراق، البعث والأكراد، دار المختار،

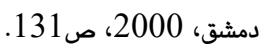

51. شازين هيرش، بةلَطةنتامة، ثارتى ديموكراتى كوردستاني عيرَاق لةضةندين

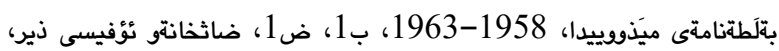

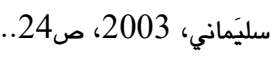

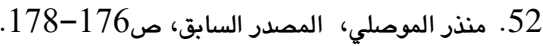

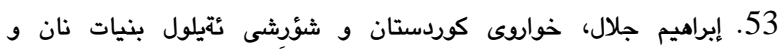

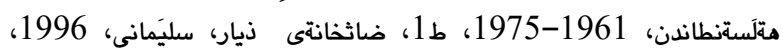
.228-221

54. دزةتيى، محسن، احداث حاصرتها، ج2، ط2 2اء، مطبعة وزارة التربية، منشورات دار اراس، اربيل، صنيك، منس، 145-149.

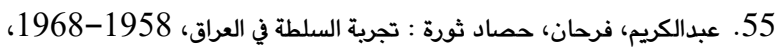

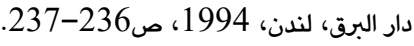
56. عمر، شورِ حسن ، حقوق الشعب الكوردي في الدساتير العراقية دراسة تحليلية مقارنة، رسالة ماجستير غير منشورة، كلية القانون، جامعة السليماتنية،

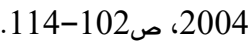
57. طؤظارى ثيَشطةوتن، تئورطاني حزبي شؤسياليستى كوردستان، عيَراق،

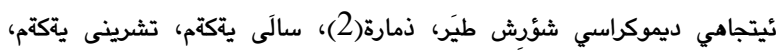

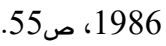

58. http://www.moqate.com/openshare/Behoth/siasia 21/Akrad/sec/63.htm 11/2/2014.

59. http://www.moqate.com/openshare/Behoth/siasia 21/Akrad/sec/63.htm 11/2/2014.

60. http://www.moqate.com/openshare/Behoth/siasia 21/Akrad/sec/63.htm 11/2/2014.

61. http://www.moqate.com/openshare/Behoth/siasia 21/Akrad/sec/63.htm 11/2/2014.

62. وجيه دويدري رجاء ، البحث العلمي (أساسيات النظرية والممارسة

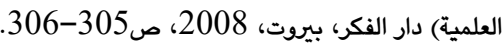

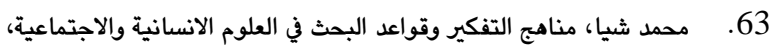

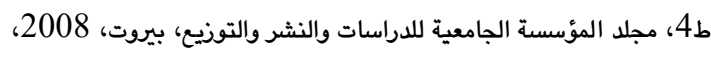

$$
\text { ص ص1910 (n) }
$$

\section{8. المصادر والمراجع}

1. أحمد، كمال مظهر ، كوردستان في سنوات الحرب العالمية الأولى، التحقيق

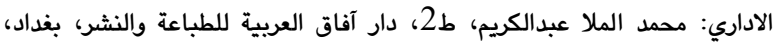
.1994

2. إدريس، ثابت عبدالرحمن، التفاوض استراتيجيات وتكنيكات ومهارات تطبيق،

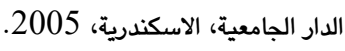
3. أدموندز، س.ج، كرد وترك وعرب سياسة ورحلات ويحوث عن الشمال الشرقي

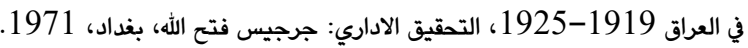
4. آرون ، ريموند ، أفيون المثقفين، ت: عادل زيتوني، منشورات المكتبة الأهلية،

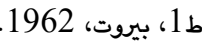
5. البارزانى، مسعود، بارزان و بزوتنةوةى رزطارى خوازى كورد 1931-

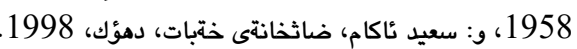

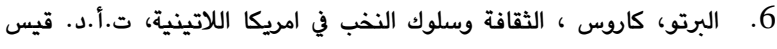

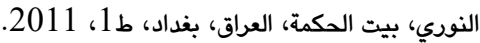


42. فتح الله، جرجريس، يقضة الكورد وتاريخ سياسي، 1900-1925، ط1، ارب، مطبعة وزارة التربية، اربيل، 2002.

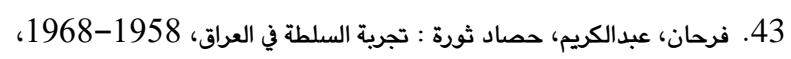
دار البرق، لندن، 1994 ( 199 44. فودة، عزالدين، ما الدبلوماسية، القاهرة، المكتبة الثقافية، د.ت.

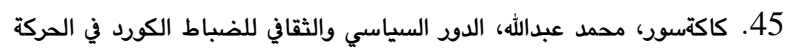
الكوردية في كوردستان الجنوبية، 1921-1945، كائهور، مسالة ماجستير غير منشورة، كلية الآداب، قسم التاريخ، جامعة صلاح الدين، اربيل، 1998 كوردستان الجنوبة، 196

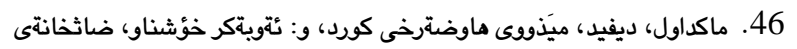

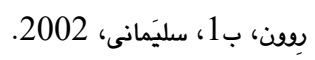
47. ناجي (شوقي) و أبو التمن (عباس غالي) ، التفاوض، مهارة واستراتيجية-

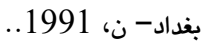
48. ناجي معروف، آصالة الحضارة العربية، بيروت، 19، دار دار المعارف، 1979.

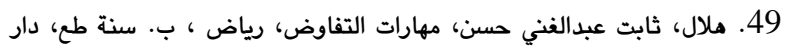

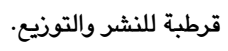

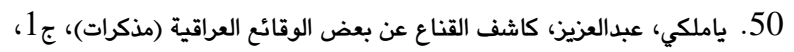
مطبعة دار المعرفة ، بغداد، 1957 الميد العزئ

1. Kennedy, 6.6 Ben Son, J-and Mcmilan,J, Managing Ne gto I ation- London: H4tch in Son Business Books, Limited (1987)

2. Pareto, Traitede sociologie generale Droz, Paris. 1968, p.72,5, cite par R-gschwar tzenberg, op. cit.

3. http://www.moqate.com/openshare/Behoth/siasia21 /Akrad/sec/63.htm 11/2/2014.
32. شيا، محمد، مناهج التفكير وقواعد البحث في العلوم الانسانية والاجتماعية،

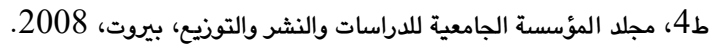

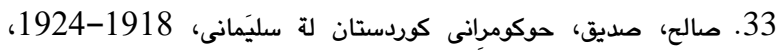

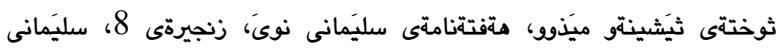
.2003

34. طؤظارى ثَيَطةوتن، نئورطاني حزبي شؤسياليستى كوردستان، عيَراق،

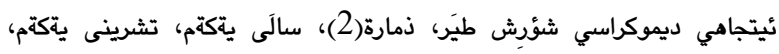
.1986

35. عبدالحميد، صلاح محمد، فن التفاوض والدبلوماسية، ط1، القاهرة، مؤسسة

طية للنشر والتوزيع، 36 عبدال 2011.

36. عبدالرحمن، ميفان عارف، الحركة القومية الكوردية التحرية في كوردستان

الجنويية، 14 تموز 1958.شباط 1963، رسالة ماجستير غير منشورة، جامعة صلاح الدين، اربيل، 2002. 37. علي (محمد) و عوض (محمد)، المدخل الى فن المفاوضات، عمان، ط1، الدئ، دار

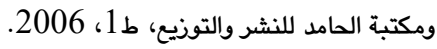
38. علي (محمود) و عوض (محمد)، المدخل الى المفاوضات، ط1، مكتبة الحامد للنشر، عمان. 39. علي، عثمان، دراسات في الحركة الكوردية المعاصرة، ط1، طع ونشر مكتبة التفسير، أربيل، 2003.

40. عمر، شورش حسن ، حقوق الشعب الكوردي في الدساتير العراقية دراسة تحليلية مقارنة، رسالة ماجستير غير منشورة، كلية القانون، جامعة السليماتنية،

41. غانم، محمد حافظ ، مباديء القانون الدولي، القاهرة، مطبعة الحرمين، 


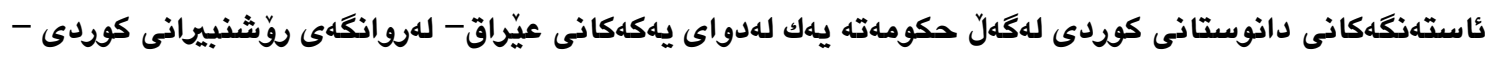
تويّرينهوهيهكى مهيدانيه-لههـريّمى كوردستان- عيّراق لهماوهى 1921- 1992

קצوخته:

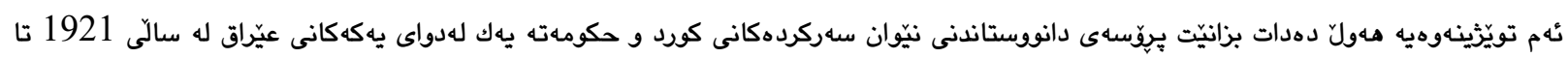

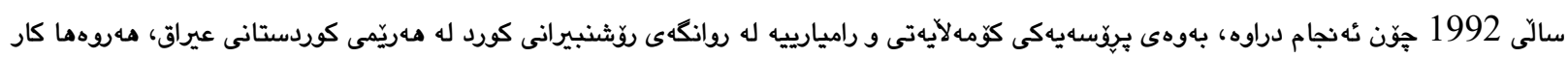

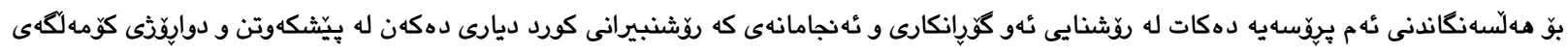
كوردى.

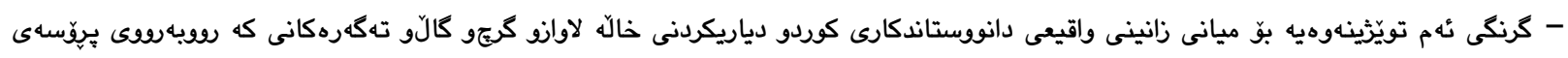
دانووستاندن بوونه تهوه.

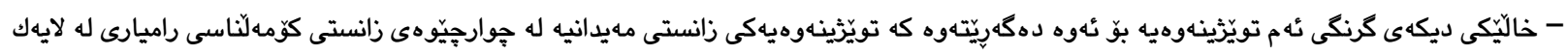

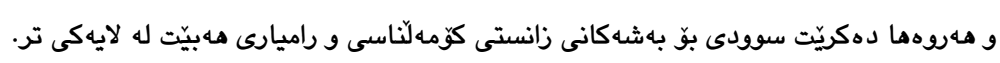

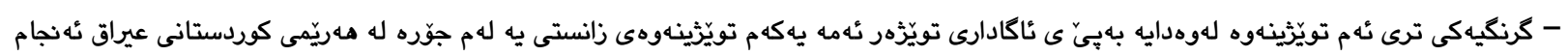
بدريّ.

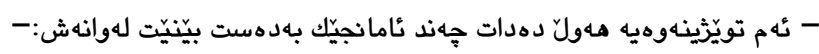
1 - خستنه يورو و دهستنيشانكردنى بنهماكانى دانووستاندن.

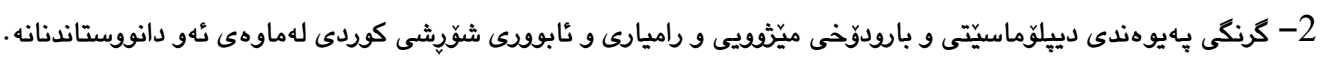

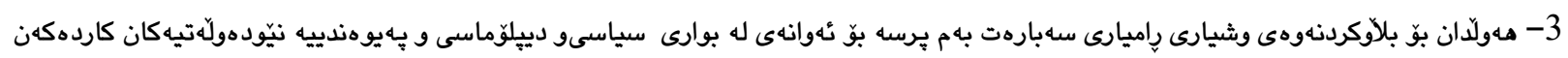

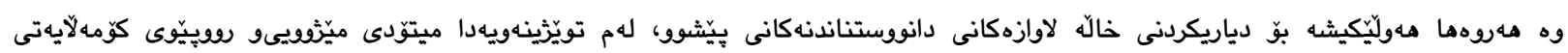
به كارهاتووه.

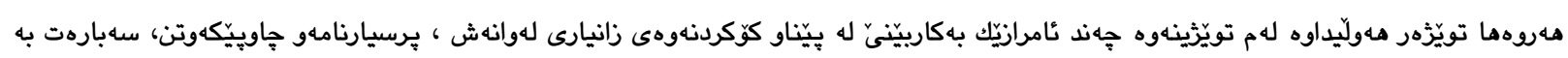

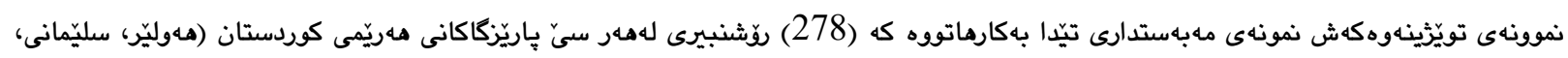
دموَك) لهخو كرتبوو.

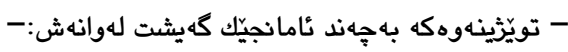

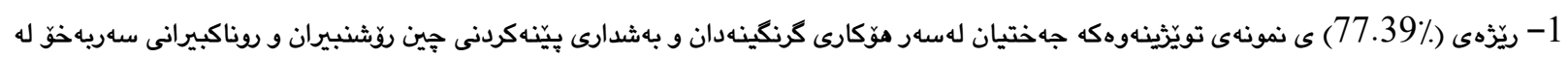
دانووستاندنهانى نيّوان حكومهته كانى عيّراق و شوّريشى كورد.

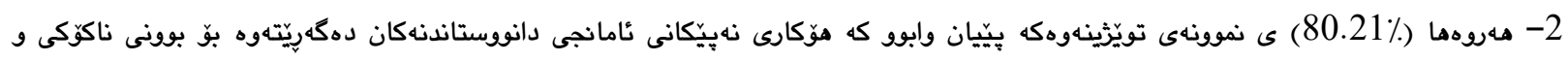
بهرزهوهندى جياواز له نيّوان سهركردهانى كورد دا.

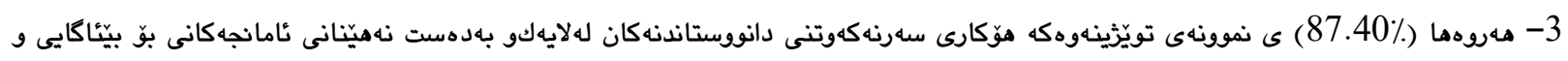

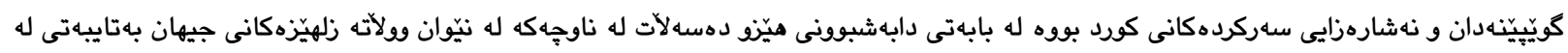
لِّزمه لآتى ناوهراست.

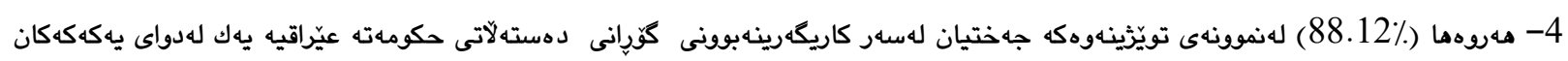

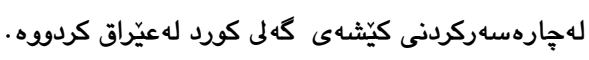

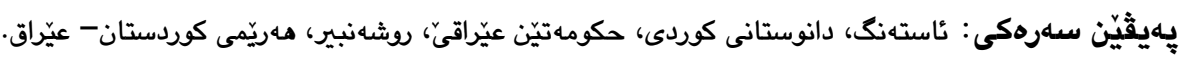




\title{
Problematic Kurdish Negotiating with Iraqi Successive Governments From 1921-1992 From the Standopint of Elite Intellectuals Consider Kurds a Field Study in Kurdistan Region
}

\begin{abstract}
:
The research is conducted to understand how the process of negotiation amongst the Kurdish leaders and Iraqi subsequent governments has been implemented from 1921until 1992; that is, it is a social and political process according to what the Kurdish intellectuals in Iraqi Kurdistan region believe. Besides, the research makes attempts to evaluate the foregoing process in terms of any changes and consequences that the Kurdish intellectuals identify for the improvement of Kurdish community in future. In fact, the significance of this research is to obtain a clear vision in indicating the reality of the Kurdish negotiators and representative as well as in identifying the weak points and obstacles facing the process of negotiation.

Obviously, this is a field-conducted research associated with sociology and politics, and also it could be, to certain extend, useful for some other branches of sociology and politics.

As far as the researcher is concerned, this is the first scientific research conducted in Kurdistan regional government. This study is to obtain several goals, they are:

1- Displaying and categorizing the principles of negotiation.

2- The significance of diplomatic relation and historical, political and economic condition of the Kurdish revolution during the negotiation.

3- Making effort to scatter political awareness related to such an issue for those who are in politics and international relations; furthermore, it is an attempt for identifying the weak points of the former negotiation.

In this study the historical method has been utilized for collecting data, and the researcher has used survey (questionnaire) and provided interview as the instrument of the research Additionally, the sample of the study (variables) is purposive; that is, 278 intellectuals from Hawler, Sulaimani, Duhok have participated in this study.

We came to conclusion that:

1- $77.39 \%$ of the participants emphasized on the reason of neglecting the freelance intellectuals and thinkers in participating in negotiation between Iraqi governments and the Kurdish revolution.

2- $80.39 \%$ of the participants believed that the reason of failing in the negotiations is belongs to the dispute and quarrel among the Kurdish leaders themselves.

3- $87.40 \%$ of the participants believed that the reason of failing on the negotiations is attributed to the lack of knowledge, carefulness, and erudition of the Kurdish leaders about the division power and authority in the territory among the powerful countries particularly in the Middle-East.

$88.12 \%$ emphasized on the fact that there has not been any change among the Iraqi subsequent government in handling the Kurdish issue in Iraqi so far.
\end{abstract}

Keywords: Problematic, Kurdish Negotiating, Iraqi Successive Governments, Intellectuals, Kurdistan Region -Iraq. 